Research report

\title{
Muscular effort coding in action representation in ballet dancers and controls: Electrophysiological evidence
}

\author{
Andrea Orlandi*, Silvia D'Incà, Alice Mado Proverbio \\ Neuro-MI, Milan Center for Neuroscience, Dept. of Psychology, University of Milano-Bicocca, Italy
}

\section{H I G H L I G H T S}

- Dancers and controls were shown technical ballet gestures during EEG recording.

- Effortful and effortless movements were compared.

- Effortful steps elicited a larger P300 and parietal LP (late positivity) in dancers.

- Visuomotor regions were more active in dancers than controls in LP time window.

- Expertise was required for an automatic and more refined coding of muscular effort.

\section{A R T I C L E I N F O}

\section{Keywords:}

Dance expertise

Action Observation Network

ERP

Superior temporal gyrus

Kinematics

Effort

\begin{abstract}
A B S T R A C T
The present electrophysiological (EEG) study investigated the neural correlates of perceiving effortful vs. effortless movements belonging to a specific repertoire (ballet). Previous evidence has shown an increased heart and respiratory rate during the observation and imagination of human actions that require a great muscular effort. In addition, TMS (transcranial magnetic stimulation) and EEG studies have evidenced a greater musclespecific cortical excitability and an increase in late event-related potentials during the observation of effortful actions. In this investigation, fifteen professional female ballet dancers and 15 controls with no experience whatsoever with dance, gymnastics, or martial arts were recruited. They were shown 326 short videos displaying a male dancer performing standard ballet steps that could be either effortful or relatively effortless. Participants were instructed to observe each clip and imagine themselves physically executing the same movement. Importantly, they were blinded to the stimuli properties. The observation of effortful compared with effortless movements resulted in a larger P300 over frontal sites in dancers only, likely because of their visuomotor expertise with the specific steps. Moreover, an enhanced Late Positivity was identified over posterior sites in response to effortful stimuli in both groups, possibly reflecting the processing of larger quantities of visual kinematic information. The source reconstruction swLORETA performed on the Late Positivity component showed greater engagement of frontoparietal regions in dancers, while task-related frontal and occipitotemporal visual regions were more active in controls. It, therefore, appears that, in dancers, effort information was encoded in a more refined manner during action observation and in the absence of explicit instruction. Acquired motor knowledge seems to result in visuomotor resonance processes, which, in turn, underlies enhanced action representation of the observed movements.
\end{abstract}

\section{Introduction}

The present study investigated the time course and neural correlates of effort encoding during the observation of complex action (i.e., ballet steps), by comparing electrophysiological responses from groups with different levels of acquired ballet expertise. Over the last decades, several lines of evidence have suggested a hierarchical (Cattaneo et al.,
2010; Grafton and Hamilton, 2007; Kilner, 2011) and functional (Handjaras et al., 2015; Ricciardi et al., 2013) organization of action representation in the human brain. Several distributed and interconnected brain regions, known as Action Observation Network (AON; Bonini, 2016; Hardwick et al., 2018), seem to underpin action perception. The AON encompasses frontoparietal (Gazzola and Keysers, 2008; Rizzolatti and Sinigaglia, 2010; 2016) and occipitotemporal

\footnotetext{
* Corresponding author at: Department of Psychology, Sapienza University of Rome, Via dei Marsi 78, 00185 Rome, Italy.

E-mail addresses: a.orlandi5@campus.unimib.it, andrea.orlandi@uniroma1.it (A. Orlandi), mado.proverbio@unimib.it (A.M. Proverbio).
} 
regions, which appear to be predominantly involved in the coding of different action features (e.g., kinematics, goals/intentions, outcome; Hamilton and Grafton, 2006, 2007).

For instance, increased activity in the inferior frontal gyrus (IFG) and intraparietal sulcus (IPS) has been previously associated with the encoding of intentions and goals of others during the observation of their actions (Catmur, 2015; Iacoboni et al., 2005). These regions, along with the premotor cortex (PM), inferior parietal lobule (IPL), and superior temporal sulcus (STS) seem to show visuomotor properties, being active during both action execution and observation (Binder et al., 2017; Caspers et al., 2010; Cattaneo and Rizzolatti, 2009). For this reason, they appear to be, for humans, analogous of the mirror neurons discovered in the ventral premotor cortex (F5 area) of primates (Di Pellegrino et al., 1992; Gallese et al., 1996). In addition, the occipitotemporal cortex (OTC) incorporates associative visual areas selectively activated by the observation of the human bodies, faces, and motion. Respectively, this includes the extrastriate (EBA) and fusiform (FBA) body areas (De Gelder et al., 2015; Peelen and Downing, 2007), the occipital (OFA) and fusiform (FFA) face areas (Haxby et al., 2000; Rossion, 2014), and human middle temporal complex (hMT+; Grossman et al., 2006).

Despite an extensive investigation of action observation processes, a series of questions remain unsolved. For instance, contrasting evidence has been reported on the contribution of OTC and visuomotor regions in action preparation and comprehension (Amoruso et al., 2011; Lingnau and Petris, 2012; Tucciarelli et al., 2015). Besides, effort encoding during action observation unveils the importance of further investigation on the role of the AON and mentalizing system (Frith and Frith, 2006) in action representation (Alaerts et al., 2010a; Mizuguchi et al., 2016). In this regard, the modulation of the muscular effort has been extensively used as a tool to investigate the resulting fluctuation of motor and premotor activity in observers' action representation (Alaerts et al., 2010a; Mizuguchi et al., 2016; Proverbio et al., 2009). A few physiological studies have shown increased autonomic functions (i.e., heart and breath rate) as a result of observation and imagination of very effortful actions when compared with less demanding actions. Raised breath rate has been reported when observing an actor walking on a treadmill at increasing speed (from walking to running) or doing a weight-lifting sequence compared to rest (Paccalin and Jeannerod, 2000). Previously, imagined walking speed has shown to be correlated with changes in the heart rate and pulmonary ventilation of the volunteers (Decety et al., 1991). According to these authors, such findings potentially indicate an autonomic anticipation of metabolic requirements needed for motor planning.

In the case of simple action observation, specific recruitment of motor regions in effort encoding has been found by many TMS (transcranial magnetic stimulation) studies. TMS pulse delivered on M1 (primary motor cortex) during the observation and execution of object grasping and lifting leads to modulation of corticospinal excitability as a function of the object weight (Alaerts et al., 2010a). Larger MEPs (motor evoked potential) are evoked by both tasks involving heavy compared with light objects. This modulation seems to be muscle-specific, elicited by both body (i.e., muscle contraction) and trajectory (i.e., object displacement in the vertical plane) information, and influenced by expertise (Alaerts et al., 2009; 2010b, 2012; Avenanti et al., 2007; Valchev et al., 2015). At the same time, the stimulation of IFG (Pobric and Hamilton, 2006) and SMA (Zénon et al., 2015) seems to affect the estimation of the weight and effort required for object lifting, respectively.

An alternative perspective, proposed by Mizuguchi and colleagues (2016), suggests that effort encoding is modulated by the activity of the mentalizing system, known to underly the understanding and attribution of mental states to another individual (Frith and Frith, 2006). In that study, the volunteers were presented with videos depicting a thin (slight) or built (muscular) actor executing repetitive dumbbell curls using different weights. Engagement of TPJ (temporo-parietal junction) and STS, but not other regions of the AON, was found when the thin (vs. the built) actor was lifting heavy weights. Although these findings support the role of the mentalizing system in effort encoding, they are possibly confounded by contextual information (i.e., fearing that the thin actor was harmed through the use of heavy weights) and requires further research.

From an electrophysiological perspective, a previous study from our research group (Proverbio et al., 2009) reported a larger late positivity (LP) component (event-related potential, ERP) elicited by the observation of static images depicting dynamic/effortful actions (i.e., running, jumping) compared with static/effortless actions (i.e., reading, eating). This potential was maximal over frontal and centro-parietal sites (from $350 \mathrm{~ms}$ onset) and was interpreted as an index of increased body kinematic information to be encoded. The source reconstruction (swLORETA) in the LP time-window showed enhanced activities in visuomotor regions in response to dynamic/effortful (vs. static/effortless) implicit motion, including the EBA, MT, STG (superior temporal gyrus), PM, M1, and IFG.

In the present study, video stimuli were used instead of static frames to investigate the time course (using EEG technique) and neural correlates of the perception of action progression, since videos increase the presence of observable movement kinematic parameters (Aglioti et al., 2008). In particular, complex action (ballet steps) representation was studied by modulating both the motor content (required effort) of the action and the observers' visuomotor expertise (ballet dancers vs. controls). If action effort representation is underpinned by visuomotor processes, we should find a between-group difference in ERP modulation since the lack of specific motor expertise in control participants (vs. dancers).

Frameworks utilizing acquired expertise with dance (Calvo-Merino et al., 2005, 2006; Kirsch and Cross, 2015; Orlandi et al., 2017), music (Pau et al., 2013; Proverbio and Orlandi, 2016), and sports (Abreu et al., 2012; Smith et al., 2016) have made valuable contribution to the study of action representation. First of all, intensive and extensive visuomotor training leads professionals to acquire fine motor skills together with increases in neural plasticity in the structural, functional, and connectivity domains (Giacosa et al., 2016; Karpati et al., 2017; Vaquero et al., 2016). Secondly, expert and familiar observers show enhanced activity of the AON during repertoire specific observation (Buccino et al., 2004; Gardner et al., 2015; Cross et al., 2009). Thirdly, a more refined ability to extract information from body and action kinematics has been shown in experts, as suggested by the highly accurate perception of small variations (Calvo-Merino et al., 2010; Orlandi et al., 2017) or macroscopic errors (Amoruso et al., 2014; Panasiti et al., 2016) in technical movements and outcome prediction compared to novices (Abreu et al., 2012; Aglioti et al., 2008; Makris and Urgesi, 2014). In particular, the dance framework (as opposed to other sports) allowed for comparisons between kinematically similar technical gestures (i.e., développé at $45^{\circ}$ vs. $120^{\circ}$ ), varying in the level of effort required. There exists a larger variety of movements within dance than in other sports repertoires (i.e., golf shot, shot on goal in football), and all dancers with a formal training (i.e., academy) share the knowledge and motor skills required to perform the movements.

Here, professional ballet dancers and controls were presented with 326 short videos $(2000 \mathrm{~ms})$ representing both very effortful and relatively effortless technical ballet steps (see Fig. 1). The maximum peak of effort was synchronized at $1000 \mathrm{~ms}$ in all videos. While being recordedd by EEG, participants were instructed to observe each movement and subsequently imagine themselves reproducing it (see Fig. 2). As in the study by Proverbio and colleagues (2009), we expected to find an increased LP component in control participants in response to effortful (vs. effortless) movement arising from the relative increase in kinematic detail (i.e., muscular contractions, speed of leg movements) during encoding. Modulation of the LP amplitude has been previously reported as a function of stimulus content (Bradley et al., 2007), in terms of emotional (Bayer and Schacht, 2014), semantic (Sitnikova et al., 2003, 


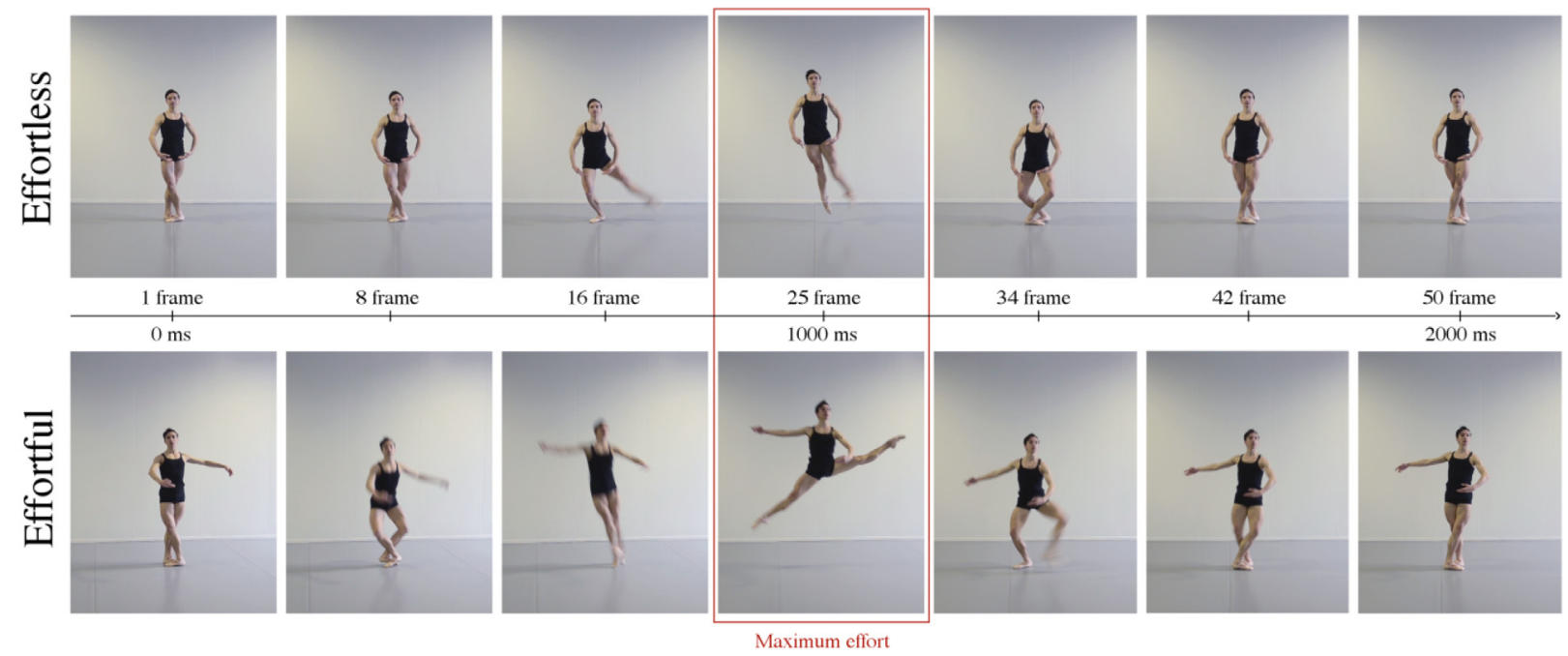

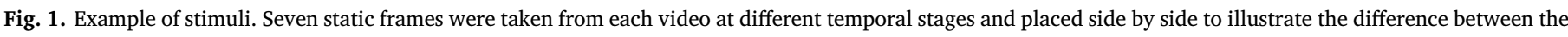

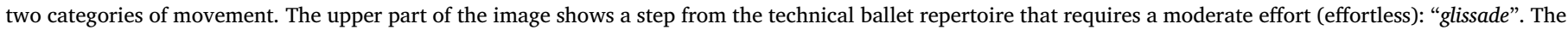

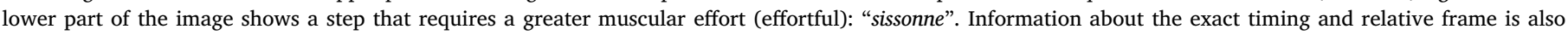
reported. The maximum peak of effort was synchronized at approximately $1000 \mathrm{~ms}$ (25 frames) in all the videos.

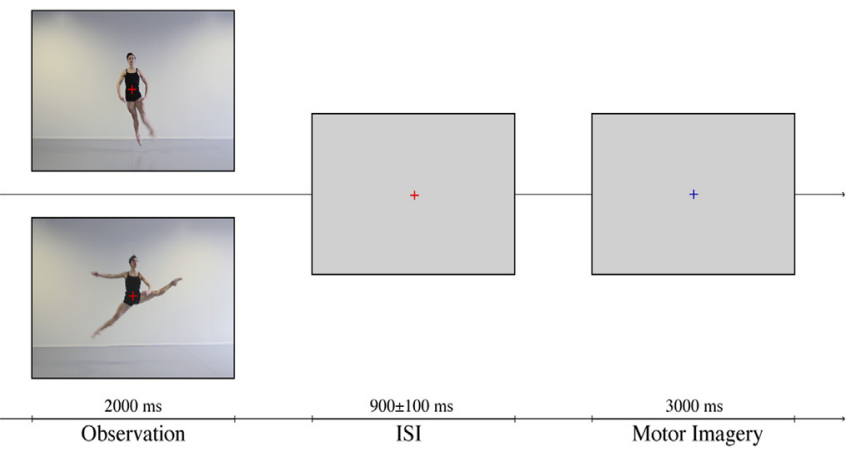

Fig. 2. Time scale of experimental design. Each video (that lasted $2000 \mathrm{~ms}$ ) was presented at the center of the screen and followed by a red fixation cross on an isoluminant light grey background. After $900 \pm 100 \mathrm{~ms}$ (interstimulus interval, ISI), the red cross turned into blue (visual cue), while the background remained the same $(3000 \mathrm{~ms})$. The participants were instructed to observe each movement (observation phase) and to kinematically image to perform it (imagery phase), as soon as the fixation cross changed color. Each trial lasted at about $6000 \mathrm{~ms}$.

2008; Orlandi et al., 2017), or kinematic information (Proverbio et al., 2009).

Moreover, we hypothesized to find refined effort coding ability (i.e., visuomotor processing) in dancers due to specific knowledge of the motor program, likely recalled during action observation (Cross et al., 2006, 2009; Orgs et al., 2008). Previous evidence has shown the occurrence of expertise-related fine-tuned resonance processes (Grafton, 2009; Kilner et al., 2007) underlying action observation in experts (i.e., pianists) and reduced cognitive resources required for its actual execution (Pau et al., 2013), consistent with a "neural efficiency" perspective (Babiloni et al., 2010). Also, larger positive potentials have been reported over frontal sites in response to subsequently recognized (vs. unrecognized) stimuli, likely indexing better encoding processes (Dolcos and Cabeza, 2002; Mangels et al., 2001). Hence, we expected to observe an increased frontal positivity response (P300-like component) with increasing action effort in dancers, with a maximal amplitude concurrent with the strongest peak effort displayed (at $1000 \mathrm{~ms}$ ) in the videos. Consequently, the source reconstruction (swLORETA) was expected to identify greater expertise-related recruitment of frontoparietal visuomotor regions in dancers, consistent with previous evidence on simple action (i.e., object grasping and lifting; Alaerts et al., 2009; 2010b) and implicit motion (Proverbio et al., 2009) perception. At the same time, enhanced engagement of occipitotemporal visual areas and prefrontal working memory regions in controls would suggest increased cognitive demands caused by enhanced processing of kinematic information (Pau et al., 2013).

\section{Results}

\subsection{Frontal P300 (1050-1250 ms)}

The amplitude values of the P300 component (in the 1050-1250 ms time-window) were subjected to a repeated-measures ANOVA with one between-groups factor (group: dancers, controls) and three withingroups factors, including: effort (effortful, effortless), hemisphere (left, right), and electrode (Fp1-2, AFp3h-4h). The complete list of significant and non-significant statistical effects can be found as Supplementary Table 1.

The ANOVA revealed a significant main effect of the effort factor [F $\left.(1,28)=35.74, p<0.0001, \eta_{p}^{2}=0.56\right]$. A larger positivity was elicited by the observation of effortful $(5.49 \mu \mathrm{V}$; SE $=0.47)$ than effortless stimuli $(3.96 \mu \mathrm{V}$; $\mathrm{SE}=0.34)$.

Further, a significant interaction between effort and group factors [F $\left.(1,28)=6.54, p<0.02, \eta_{p}^{2}=0.19\right]$ and the relevant Tukey's posthoc test showed that the difference in P300 amplitude in response to effortful vs. effortless stimuli was significant only in the dancer group (effortful: $6.33 \mu \mathrm{V} ; \mathrm{SE}=0.67$; effortless: $4.13 \mu \mathrm{V} ; \mathrm{SE}=0.48$; $p<0.0002$ ). Contrarily, it did not reach the significance level in the control group (effortful: $4.66 \mu \mathrm{V}$; $\mathrm{SE}=0.67$; effortless: $3.78 \mu \mathrm{V}$; $\mathrm{SE}=0.48 ; p=0.097$ ). The ERP waveforms and the boxplots illustrating the amplitude of the P300 component are shown in Figs. 3 and 4.

Lastly, the significant main effect of the hemisphere factor $[\mathrm{F}(1$, 28) $\left.=5.77, p<0.03, \eta_{p}^{2}=0.17\right]$ indicated a larger positivity over the left $(4.83 \mu \mathrm{V}$; SE $=0.40)$ than right hemisphere $(4.62 \mu \mathrm{V} ; \mathrm{SE}=0.38)$ in this latency range.

\subsection{Late positivity (1400-1600 ms)}

The amplitude values of the LP component (in the 1400-1600 ms time-window) were subjected to a repeated-measures ANOVA with one between-groups factor (group: dancers, controls) and three within- 

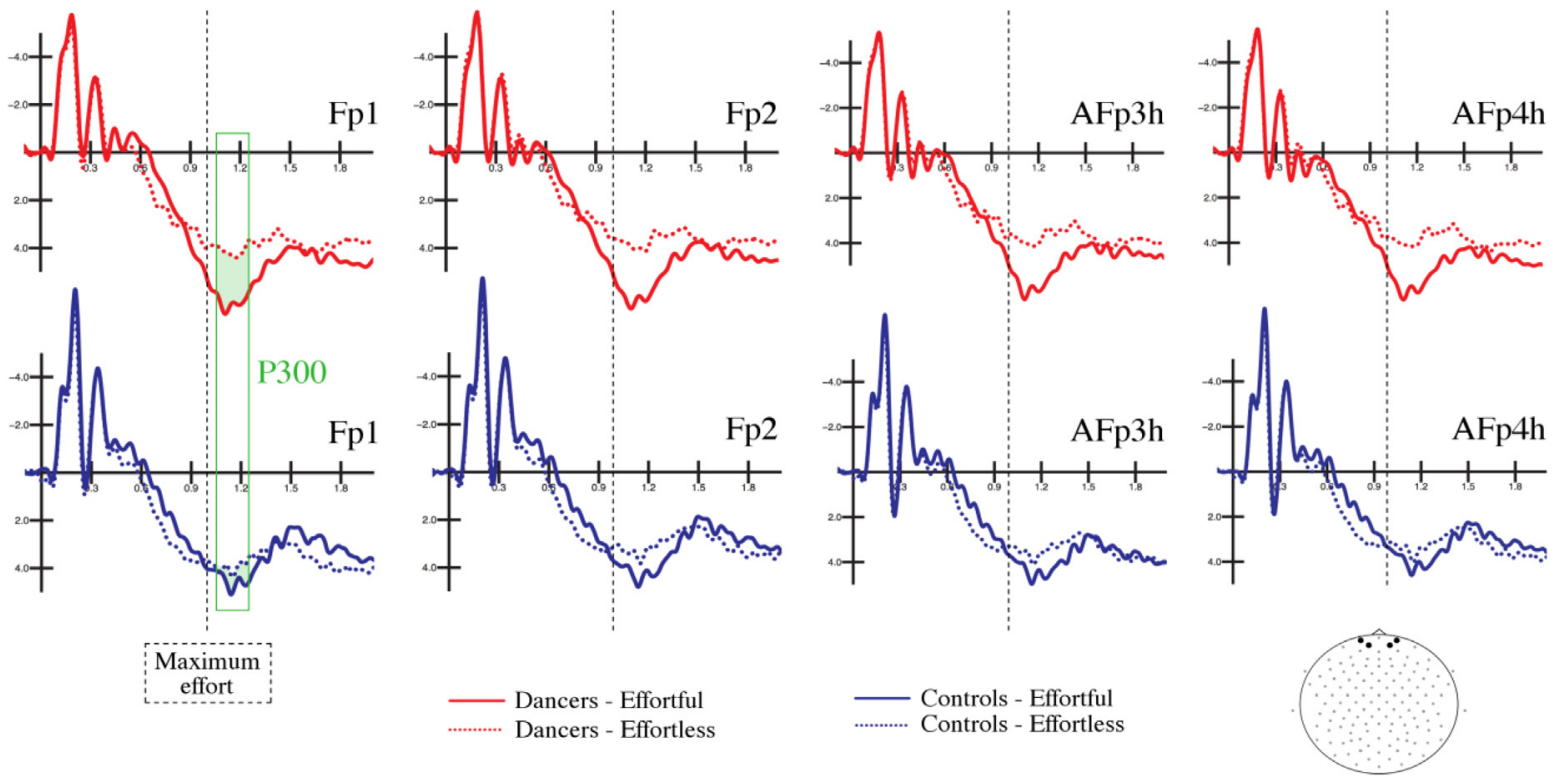

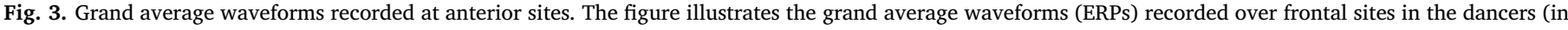

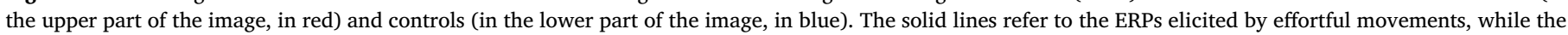

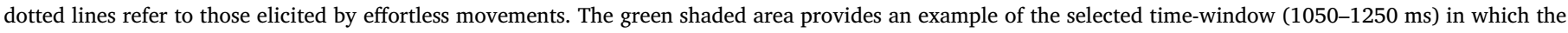
mean area voltage was quantified. The vertical dotted lines represent the peak of maximum effort visible in each video at 1000 ms.

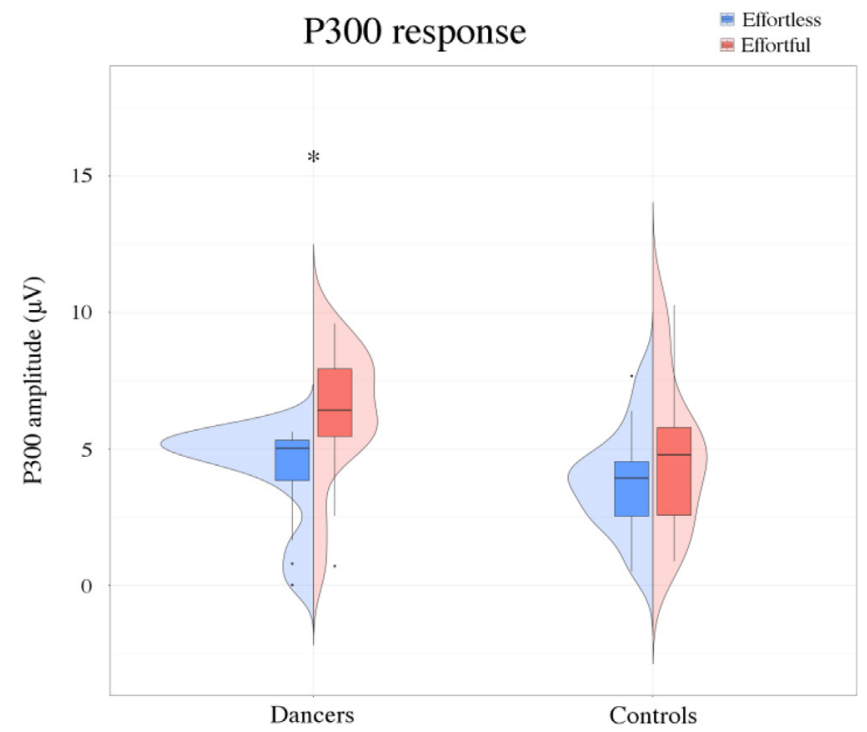

Fig. 4. Amplitude values of $\mathrm{P} 300$ component. The boxplot and density plots illustrate the mean amplitude values $(\mu \mathrm{V})$ of the P300 recorded at frontal sites as a function of effort degree and group of participants. A greater positivity (P300) in response to effortful (in red) vs. effortless (in blue) stimuli was found only in the dancers.

groups factors, including: effort (effortful, effortless), hemisphere (left, right), and electrode (P1-2, POO3h-4 h). The complete list of significant and non-significant statistical effects can be found as Supplementary Table 2.

The ANOVA showed a significant main effect of the effort factor [F $\left.(1,28)=15.92, p<0.001, \eta_{p}^{2}=0.36\right]$. A larger positivity was found in response to effortful $(2.41 \mu \mathrm{V} ; \mathrm{SE}=0.38)$ than standard effort stimuli $(1.70 \mu \mathrm{V}$; SE $=0.36)$.

The electrode factor was also statistically significant $[\mathrm{F}(1$, $28)=49.45, p<0.0001, \eta_{p}^{2}=0.63$ ], showing a larger positivity over parietal sites (P1-P2:2.89 $\mu \mathrm{V}$; SE $=0.36$ ) than occipito-parietal sites (POO3h-POO4h:1.22 $\mu \mathrm{V}$; SE $=0.40$ ).

Further, the significant triple interaction between effort, group, and electrode factors $\left[\mathrm{F}(1,28)=8.25, p<0.01, \eta_{p}^{2}=0.23\right]$, and the relevant posthoc comparisons, showed that LP elicited by effortful vs. effortless stimuli was larger $(p<0.0002)$ over both parietal (effortful: $2.96 \mu \mathrm{V} ; \mathrm{SE}=0.55$; effortless: $1.95 \mu \mathrm{V} ; \mathrm{SE}=0.50$ ) and occipito-parietal (effortful: $1.08 \mu \mathrm{V}$; $\mathrm{SE}=0.60$; effortless: $0.17 \mu \mathrm{V}$; $\mathrm{SE}=0.57$ ) sites in the dancers only. Contrarily, a significant difference $(p<0.0002)$ was found only over occipito-parietal sites (effortful: $2.20 \mu \mathrm{V}$; $\mathrm{SE}=0.60$; effortless: $1.46 \mu \mathrm{V}$; SE $=0.57$ ), but not over parietal sites $(p=0.64)$, in the controls. The ERP waveforms and the boxplots illustrating the amplitude of the LP component are shown in Fig. 5 and Fig. 6.

Lastly, the significant interaction between effort and hemisphere factors $\left[\mathrm{F}(1,28)=4.83, p<0.04, \eta_{p}^{2}=0.15\right]$, and the relative posthoc test, showed a larger positivity elicited by effortful than effortless stimuli over both left (effortful: $2.41 \mu \mathrm{V}$; $\mathrm{SE}=0.40$; effortless: $1.80 \mu \mathrm{V} ; \mathrm{SE}=0.38$ ) and right (effortful: $2.42 \mu \mathrm{V}$; SE $=0.38$; effortless: $1.60 \mu \mathrm{V} ; \mathrm{SE}=0.35)$ hemispheres $(p<0.0002)$. In particular, the LP amplitude elicited by effortless stimuli was greater over left than right hemisphere $(p<0.04)$, while it was similar over both hemispheres in response to effortful stimuli $(p=1)$.

\subsection{SwLORETA source reconstruction (1400-1600 ms)}

To estimate the intracranial generators of the neural processes involved in perceiving the effort of a movement, a swLORETA source reconstruction was performed on the difference waves (see Fig. 7) obtained by subtracting the ERPs for effortless from those elicited by effortful stimuli in the LP time-window (1400-1600 ms). A list of significant active electromagnetic dipoles explaining the different surface voltage in both groups of participants is shown in Table 1 . The main active dipoles included the STG/uncus bilaterally (BA 38), the inferior temporal gyrus (ITG; BA 21), the superior frontal gyrus (SFG; BA 8/6), and the IPL/supramarginal gyrus (BA 40) in the dancers. Conversely, task-related inferior/superior/medial frontal regions (IFG/SFG/MFG; BA 10) and occipitotemporal visual areas were identified as more active in controls (see Fig. 8), including the fusiform/lingual gyrus (BA 19, 20), the middle temporal (MTG; BA 21) and occipital gyri (MOG; BA 37). 


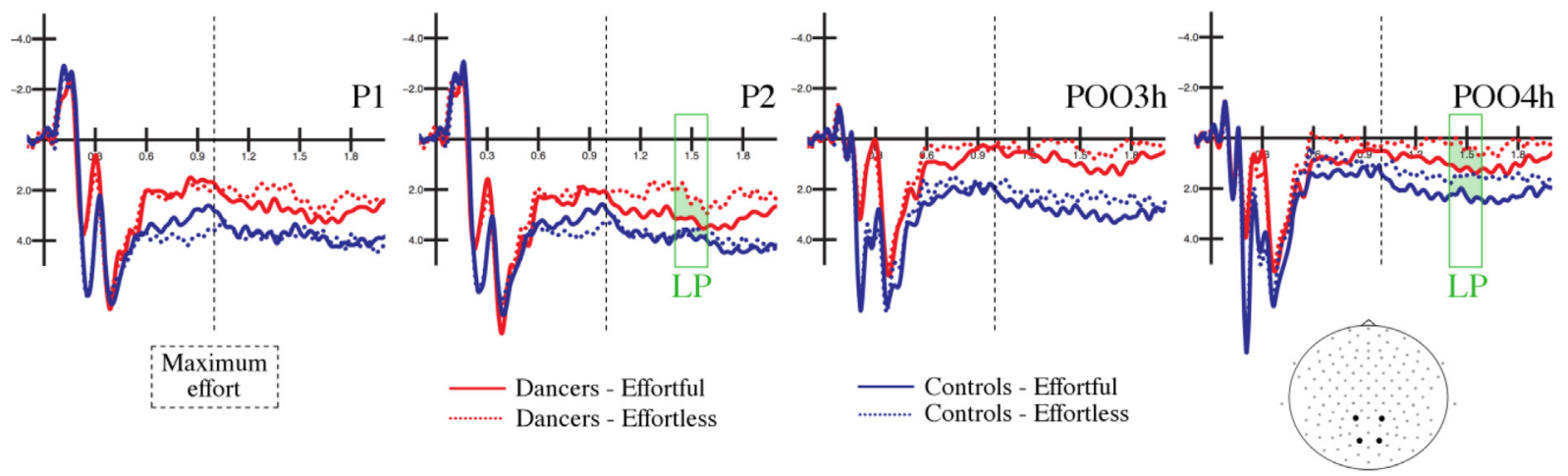

Fig. 5. Grand average waveforms recorded at posterior sites. The figure illustrates the grand average waveforms (ERPs) recorded over posterior sites of the scalp in the dancers (in red) and controls (in blue). The solid lines represent the ERPs elicited by effortful movements, while the dotted lines represent those elicited by effortless movements. The green shaded areas provide examples of the selected time-window (1400-1600 ms) in which the mean area voltage was quantified. The vertical dotted lines represent the peak of maximum effort visible in each video at $1000 \mathrm{~ms}$.

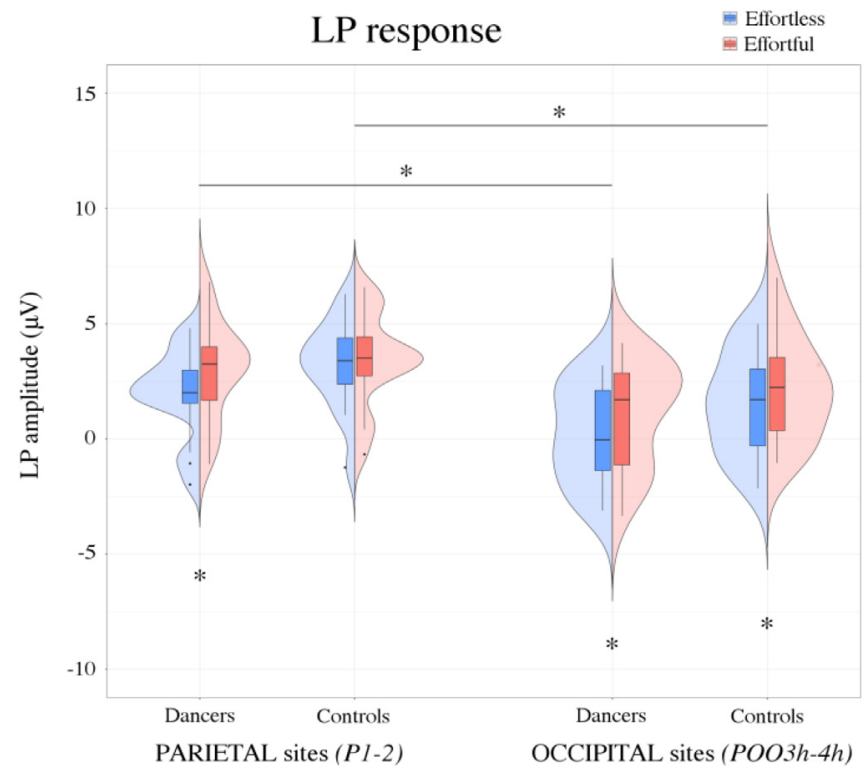

Fig. 6. Amplitude values of LP component. The boxplots and density plots illustrate the mean amplitude values $(\mu \mathrm{V})$ of the LP recorded at parieto-occipital sites as a function of effort, electrode, and group factors. A greater positivity (LP) in response to effortful (in red) vs. effortless (in blue) stimuli was found in all participants over occipital sites (POO3h-POO4h), while it also encompassed parietal sites (P1-P2) in dancers.

\section{Discussion}

Several studies have shown that the observation of simple, effortful (compared to effortless) actions (i.e., grasping and lifting objects) results in an increased corticospinal excitability, which suggests a muscleand time-dependent motor coding of the effort (Alaerts et al., 2010a: 2010b: Proverbio et al., 2009). In contrast, other authors have suggested a role of the mentalizing system (i.e., TPJ) in understanding the effort required for actions performed by other individuals (Mizuguchi et al., 2016). The present study investigated the time course and neural correlates of effort encoding in complex action (i.e., ballet steps) representation, by comparing groups with different levels of acquired ballet expertise. Therefore, the electrophysiological responses (ERP) of professional dancers and controls were compared during the observation of technical gestures that differed on the base of the required effort, intended as the amount of force exerted during the reproduction of a movement (Chiu, 2018). Effort-related information modulated the ERP responses over frontal and parietal regions in the dancer group when compared with the control group, suggesting enhanced visuomotor processing of the action.

All the video stimuli displayed the maximum peak of effort at $1000 \mathrm{~ms}$ (i.e., maximum height or spread of the legs during a jump), thus, as expected, we found a concomitant frontal positivity component (1050-1250 ms) that reached the highest amplitude at approximately $\cong 1140 \mathrm{~ms}$. This positivity was named P300 after the family of positive endogenous components (P3) classically associated with the updating of the mental representation induced by incoming stimuli (Polich, 2007), as well as target recognition (Orlandi et al., 2019a, 2019b), and categorization (Proverbio et al., 2015). It is well-known in the literature that the P3 components can be modulated by attention orientation, frequency, and novelty of the stimulus (Azizian et al., 2006; Picton, 1992), in terms of amplitude and scalp distribution (i.e., centroparietal P3 response to infrequent targets). In the present study, the amplitude of the positivity was specifically increased by the observation of effortful (vs. effortless) actions only in the group of dancers (see Fig. 4). Control participants appeared to be less sensitive to variations in effort in the P300 time-window.

In this regard, we interpreted the frontal positivity as an index of the encoding processes of the action. Previous evidence has shown enhanced anterior positivity (slow-wave) during both the encoding and recalling of low-arousal positive images subsequently remembered in a more efficient way than neutral and negative images (Dolcos and Cabeza, 2002; Koenig and Mecklinger, 2008). Increased frontal positivity has also been reported during the encoding of correctly remembered and recalled words than non-remembered words, at approximately $1000 \mathrm{~ms}$ after the stimulus onset (Mangels et al., 2001).

More specifically, since the movements presented here differed on the basis of the effort level, the P300 modulation may indicate increased action processing required for implicit effort encoding in dancers. It is, therefore, possible that specific motor knowledge acquired with visuomotor dance training has led to a refined capability to codify action parameters (including the muscular effort). Furthermore, our P300 was larger over the left than the right hemisphere. According to the HERA (hemispheric encoding/retrieval asymmetry) model of memory processes (Habib et al., 2003), a greater involvement of the left prefrontal cortex (PFC) would be associated with episodic memory encoding of an incoming stimulus, while the right PFC would be more involved with its subsequent retrieval. Hence, both the latency and distribution of the component strengthen the idea of an encoding-related P300.

At this point, it should be mentioned that integrative interpretations would also be possible and therefore must be taken into account. Namely, covert spatial attention might have a role in modulating the processes by which experts perceive effort (in action). It cannot be excluded that, based on prior motor knowledge, dancers (compared with controls) might have directed their attention toward the more 

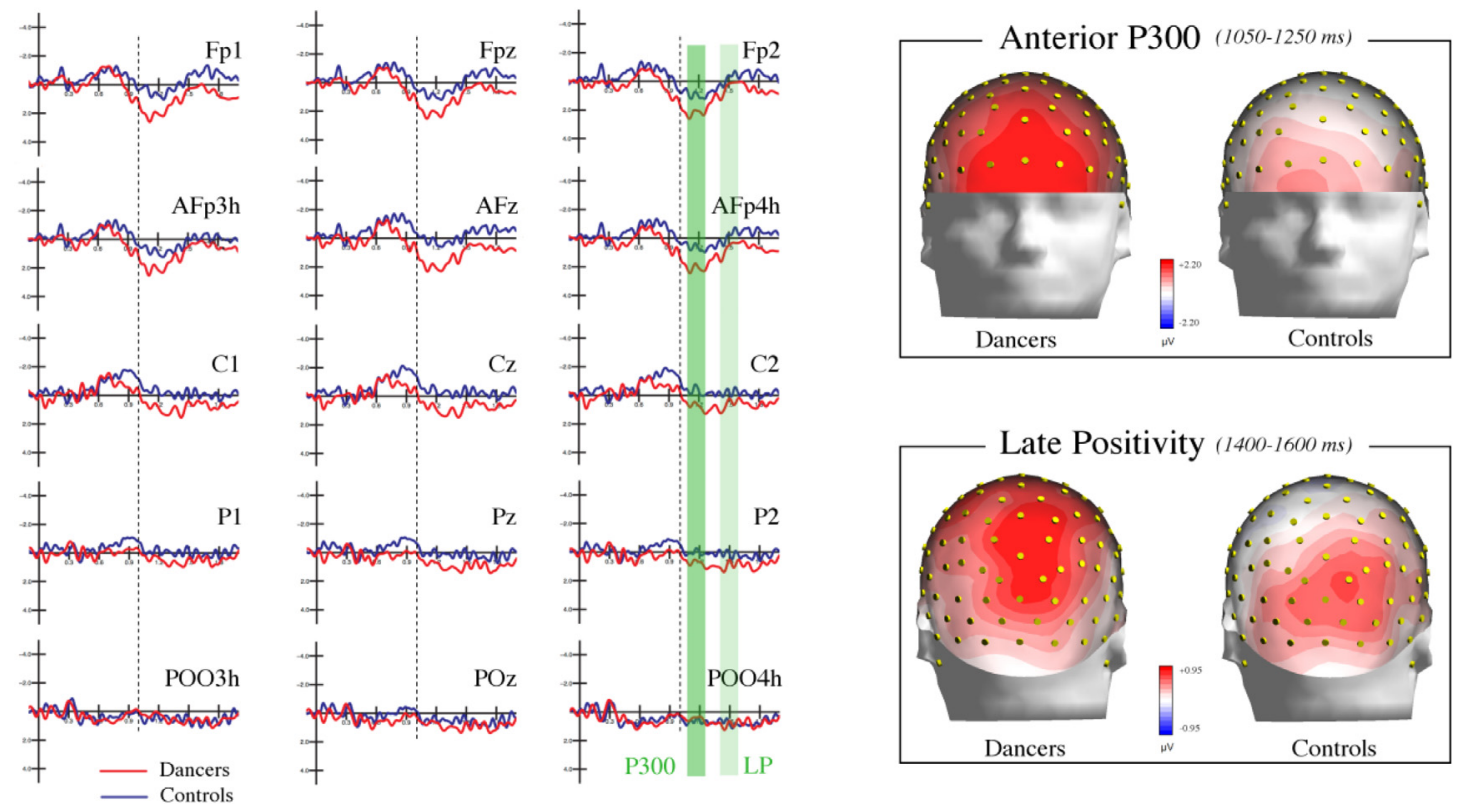

Fig. 7. Grand average difference waves (effortful minus effortless). The middle part of the image illustrates the grand averages difference waves (DW) obtained subtracting ERPs to effortful minus ERPs to effortless stimuli in the dancers (in red) and controls (in blue). The upper part of the image illustrates the topographic maps of scalp voltage distribution of the DW relative to P300 time-window (1050-1250 ms), in the dancers (on the left) and controls (on the right). The lower part of the image illustrates the topographic maps of scalp voltage distribution of the DW relative to LP time-window (1400-1600 ms), in the dancers (on the left) and controls (on the right).

salient part of the body. Also, results from the validation of the stimuli showed an underestimation of the actual effort by controls during an explicit effort evaluation. This effect may suggest that different cognitive strategies may have been implemented during action observation in the perspective of mental motor simulation in dancers and controls. Further investigation will help to clarify the relation between

Table 1

Active electromagnetic dipoles list. List of active electromagnetic dipoles identified in dancers and controls according to swLORETA in the Late Positivity timewindows (1400-1600 ms), with the relevant Talairach coordinates. The strongest sources of activation included the superior and inferior temporal gyri, supramarginal gyrus/inferior parietal lobule, and few visual areas in the dancers. The main dipoles in controls were instead located in the rostral prefrontal cortex (BA 10), and in several visual regions, especially in the right hemisphere. (Legend: Magn - magnitude, Hem - hemisphere, T - temporal lobe, $\mathrm{P}$ - parietal lobe, $\mathrm{F}$ - frontal lobe, $\mathrm{O}$ - occipital lobe, BA - Brodmann area).

\begin{tabular}{lllllll}
\hline Dancers & & & & & \\
\hline Magn & T-x $[\mathrm{mm}]$ & T-y $[\mathrm{mm}]$ & T-z $[\mathrm{mm}]$ & Hem & Lobe & Area \\
\hline 7.09 & -48.5 & 8.2 & -20 & $\mathrm{~L}$ & $\mathrm{~T}$ & Superior Temporal Gyrus \\
6.64 & -58.5 & -9.4 & -14 & $\mathrm{~L}$ & $\mathrm{~T}$ & Inferior Temporal Gyrus \\
5.81 & 60.6 & -40.6 & 34 & $\mathrm{R}$ & $\mathrm{P}$ & Supramarginal Gyrus \\
4.82 & 21.2 & 9.1 & -27.5 & $\mathrm{R}$ & $\mathrm{T}$ & Uncus/Superior Temporal Gyrus \\
4.52 & 11.3 & -69 & 13.6 & $\mathrm{R}$ & $\mathrm{O}$ & Cuneus/Posterior Cingulate Cortex \\
4.52 & 1.5 & -73 & 49.2 & $\mathrm{R}$ & $\mathrm{P}$ & Precuneus \\
4.19 & -18.5 & 30.5 & 49.8 & $\mathrm{~L}$ & $\mathrm{~F}$ & Superior Frontal Gyrus \\
3.56 & 40.9 & 55.3 & 7 & $\mathrm{R}$ & $\mathrm{F}$ & Middle Frontal Gyrus \\
2.96 & -58.5 & -31.4 & 43.8 & $\mathrm{~L}$ & $\mathrm{P}$ & Inferior Parietal Lobule \\
\hline
\end{tabular}

Controls

\begin{tabular}{|c|c|c|c|c|c|c|c|}
\hline Magn & $\mathrm{T}-\mathrm{x}[\mathrm{mm}]$ & $\mathrm{T}-\mathrm{y}[\mathrm{mm}]$ & $\mathrm{T}-\mathrm{z}[\mathrm{mm}]$ & Hem & Lobe & Area & BA \\
\hline 12.4 & -38.5 & 46.3 & -2.3 & $\mathrm{~L}$ & $\mathrm{~F}$ & Inferior Frontal Gyrus & 10 \\
\hline 9.46 & -8.5 & 65.3 & 7.9 & $\mathrm{~L}$ & $\mathrm{~F}$ & Superior Frontal Gyrus & 10 \\
\hline 8.96 & 1.5 & 57.3 & -9 & $\mathrm{R}$ & $\mathrm{F}$ & Medial Frontal Gyrus & 10 \\
\hline 7.07 & 21.2 & 55.3 & 7 & $\mathrm{R}$ & $\mathrm{F}$ & Superior Frontal Gyrus & 10 \\
\hline 6.93 & 31 & 53.4 & 24.8 & $\mathrm{R}$ & $\mathrm{F}$ & Superior Frontal Gyrus & 10 \\
\hline 5.89 & 31 & 9.1 & -27.5 & $\mathrm{R}$ & $\mathrm{T}$ & Superior Temporal Gyrus & 38 \\
\hline 5.56 & 50.8 & -0.6 & -28.2 & $\mathrm{R}$ & $\mathrm{T}$ & Middle Temporal Gyrus & 21 \\
\hline 5.17 & -48.5 & -67.1 & -3.5 & $\mathrm{~L}$ & $\mathrm{O}$ & Middle Occipital Gyrus & 37 \\
\hline 4.89 & 21.2 & -66.1 & -10.9 & $\mathrm{R}$ & $\mathrm{O}$ & Fusiform Gyrus & 19 \\
\hline 4.78 & 21.2 & -68 & 4.7 & $\mathrm{R}$ & $\mathrm{O}$ & Lingual Gyrus & 19 \\
\hline 4.77 & 11.3 & -70 & 22.5 & $\mathrm{R}$ & $\mathrm{P}$ & Precuneus & 31 \\
\hline 4.44 & 50.8 & -33.7 & -23.6 & $\mathrm{R}$ & $\mathrm{T}$ & Fusiform Gyrus & 20 \\
\hline 3.82 & 60.6 & -56.9 & -2.8 & $\mathrm{R}$ & $\mathrm{T}$ & Middle Temporal Gyrus & 21 \\
\hline 3.72 & 50.8 & 0.4 & 47.2 & $\mathrm{R}$ & $\mathrm{F}$ & Precentral Gyrus & 6 \\
\hline 2.57 & 50.8 & -32.4 & 52.7 & $\mathrm{R}$ & $\mathrm{P}$ & Inferior Parietal Lobule & 40 \\
\hline
\end{tabular}




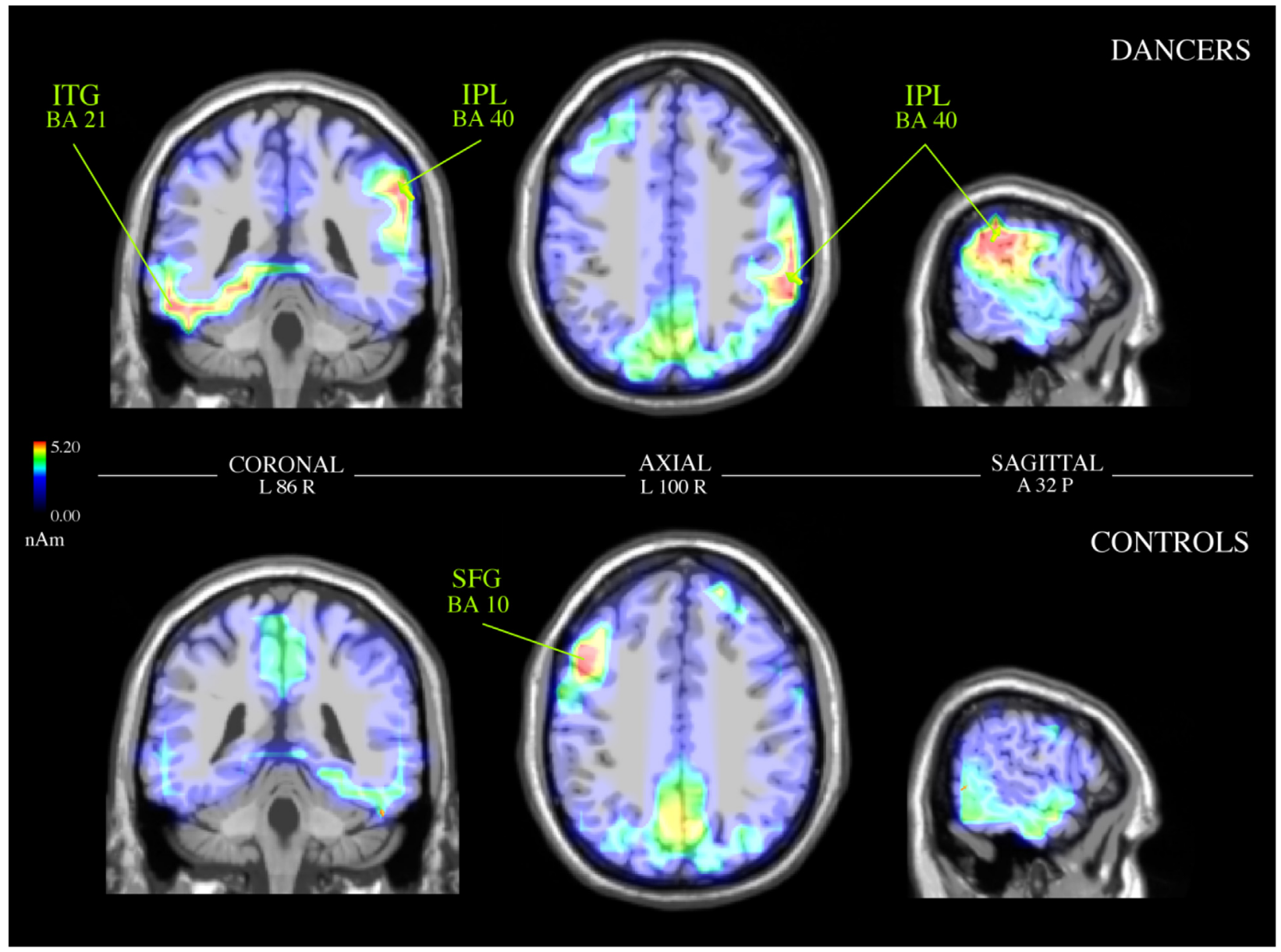

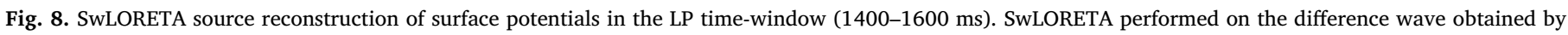

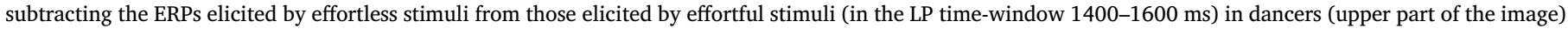

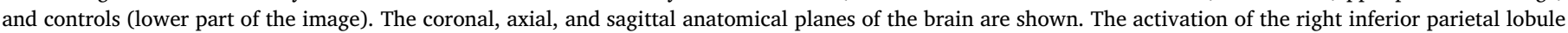

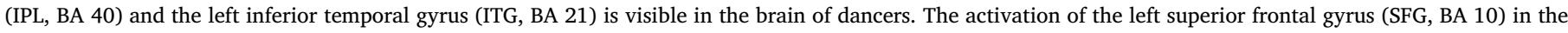
brain of the controls can also be appreciated. The strongest magnitude values of the signal (nAm) are shown in red.

action kinematics, attention allocation, and visuomotor expertise.

Another component sensitive to effort-related changes was identified over posterior sites of the scalp at a later latency (1400-1600 ms), therefore named Late Positivity (LP). The observation of effortful (vs. effortless) movements resulted in enhanced LP amplitude differently distributed on the scalp between the two groups of participants (see Fig. 6). While a modulation of the LP was visible over occipital areas in all participants, it also encompassed parietal scalp sites in dancers. The LP is a late component generally related to high-order integrative processes that is sensitive to the information content of the stimulus. For instance, the emotional valence and arousal associated with a stimulus (vs. neutral) can increase the LP amplitude (Bayer and Schacht, 2014; Codispoti et al., 2007; Schupp et al., 2000), together with selective visual attention directed towards salient parts of the stimulus (Hajcak et al., 2009, 2013). A violation of the viewer's expectancies (i.e., unexpected action end, context-related incongruency) also leads to enhancement of the LP (Giglio et al., 2013; Sitnikova et al., 2003; 2008). Moreover, our result concurs with Proverbio and colleagues (2009), in which the observation of static images depicting dynamic/ effortful (vs. static/effortless) actions led to a larger LP. Hence, the larger positivity found here over occipital sites may be attributed to the greater amount of motion and kinematic information (i.e., muscular contractions, speed of leg movements) conveyed by the effortful dance steps.

In a previous investigation of our research group (Orlandi et al., 2017), we reported a modulation of the LP component (repetition suppression effect) in response to identical vs. varied action repetition as a function of the visuomotor expertise of the observers (dancers vs. controls). In the present study, dance expertise resulted in a wider distribution of the effort-related LP over parietal sites, consistent with previous evidence on ERD (event-related desynchronization) over sensorimotor regions during action observation. In this regard, several EEG studies have shown specific reduction (suppression) of the sensorimotor $\mathrm{mu}(\mu)$ rhythm (8-12 Hz) over centro-parietal sites (Coll et al., 2017; Yin et al., 2016) during action processing. This modulation is generally considered an index of visuomotor simulation processes (Fox et al., 2016; Hobson and Bishop, 2017), that can be modulated by acquired visuomotor expertise (Denis et al., 2017; Orgs et al., 2008). Importantly, increased modulation (ERD) in the alpha frequency band (8-10 Hz) has been reported during the observation of heavy (vs. light) object lifting only in participants with acquired visuomotor (but not semantic) practice (interaction) with the objects (Quandt and Marshall, 2014). Acquired expertise modulated sensitivity to predicted sensorimotor consequences of the action. Hence, the LP evidence reported here suggest the occurrence of visuomotor resonance processes in dancers (Pau et al., 2013), together with enhanced engagement of visual areas in response to effort-related kinematics regardless of dance expertise (Proverbio et al., 2009).

The last hypothesis was further explored by applying a source reconstruction (swLORETA) on the effort-related potential (difference wave) computed for each group of participants (see Table 1). The swLORETA was performed on the effortful minus effortless brain 


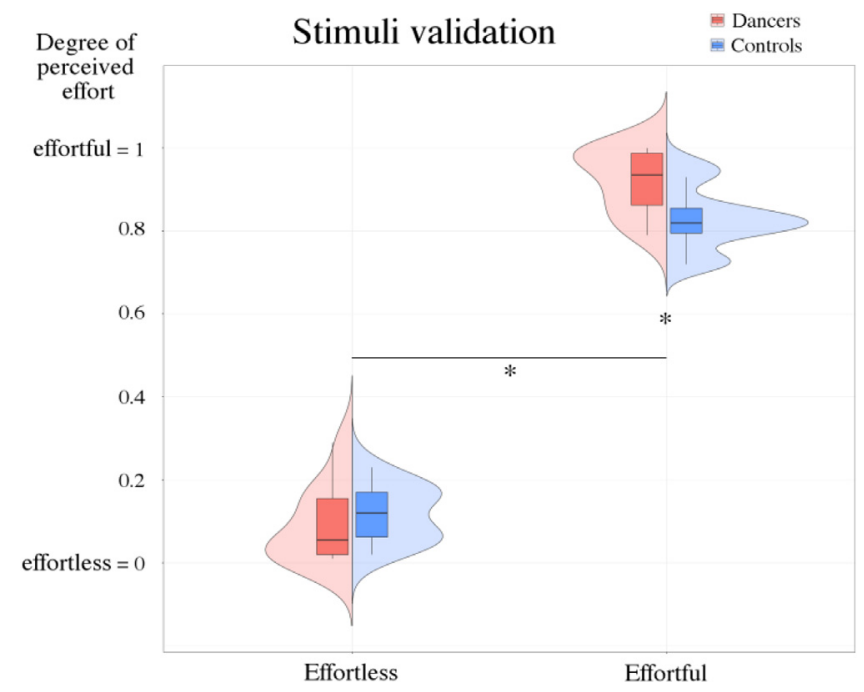

Fig. 9. Degree of perceived effort from stimuli validation. The boxplots and density plots illustrate the mean rating values of the perceived effort for the two categories of stimuli (163 effortful movements and 163 effortless movements), collected from twenty judges (dancers in red vs. controls in blue) during the validation phase. The judges were instructed to categorize each stimulus as effortful (1) or effortless (0).

potentials in the LP time-window since the significant difference between effort conditions revealed by the ANOVAs (on the LP amplitude values) in both dancers and controls. Namely, this analysis would reveal possible differences in the neural substrates underlying action encoding as a function of dance experience.

The main dipoles identified in controls included bilateral task-related frontal areas (BA 10), in addition to several temporal (BA 38, 20, 21 ) and occipital (BA 19, 37) regions on the right hemisphere. The OTC include visual areas preferentially associated to body, face, and motion perception (Haxby et al., 2000; Peelen and Downing, 2007; Grossman et al., 2006), and its engagement has been previously reported during action observation (Bonini, 2016; Ma et al., 2018). The rostral prefrontal cortex (rPFC; BA 10) is generally associated with working and prospective memory, encoding, and maintenance of new information (Benoit et al., 2011; Gilbert et al., 2006). Increased cognitive effort is also associated with enhanced engagement in BA 10 (see Fig. 9), as in the case of a secondary task overlapping the main one (Minamoto et al., 2015; Momennejad and Haynes, 2013), as well as a prospective memory task that requires incremental updating of working memory (Halahalli et al., 2015). Hence, in our study, we hypothesized enhanced cognitive load in controls (lacking in specific motor knowledge) due to increased kinematics processing in anticipation of the motor imagery task.

At the same time, enhanced activity in the bilateral (although mainly on the left hemisphere) STG (Brodmann Area, BA 38), IPL (BA 40), left ITG (BA 21), and precentral gyrus (BA 6/8) was found in dancers. The STS/STG is an associative area involved in several processes (i.e., multisensory integration) due to the multiple connections with cortical and subcortical structures (Erickson et al., 2017; Mier et al., 2014; Sokolov et al., 2012). It has a well-established role in biological motion perception, imitation, and action goal comprehension (Herrington et al., 2011; Molenberghs et al., 2010; Thompson et al., 2005), providing, for instance, visual inputs to visuomotor frontoparietal regions (Rizzolati and Craighiero, 2004). Its role in effort encoding has been previously reported (Mizuguchi et al., 2016; Proverbio et al., 2009). Substantial evidence shows an expertise-related modulation of the STG at both functional (i.e., detection of movement variation) and structural (i.e., increased cortical thickness) levels (Karpati et al., 2017; Orlandi et al., 2017). In the present study, the left STG was selectively engaged in dancers only, consistent with evidence by Kirsch and Cross
(2015), who found increased activity in left STG, left PM, and right inferior parietal cortex with increasing visuomotor expertise. Moreover, enhanced activity within the IPL (BA 40) and precentral gyrus (BA 8/6) in response to effortful gestures in dancers is consistent with evidence on action encoding in musicians (vs. controls; Pau et al., 2013). Frontoparietal regions have been extensively associated with action observation, preparation, and imagination (Arnstein et al., 2011; Buccino et al., 2001, 2004; Chong et al., 2008; Rizzolatti and Craighero, 2004), especially in response to well-known and trained actions (Cross et al., 2006, 2009; Gardner et al., 2015).

Finally, the active dipoles were more bilaterally distributed in dancers compared with controls, who showed stronger right-lateralization. Previous evidence has suggested reduced hemispherical asymmetries as a result of dance (Orlandi et al., 2019a) and musical (Moore et al., 2014; Rüber et al., 2013; Steele et al., 2013) practice. This effect may be attributed to plasticity changes occurring after intense body training (Giacosa et al., 2016; Hänggi et al., 2010), as in the case of increased grey matter (GM) volume found in the posterior hippocampal formation and in the lingual /fusiform gyri in dancers (Hüfner et al., 2011). These findings would strengthen the assumption of a more efficient visuomotor network in experts when compared with non-experts (Babiloni et al., 2010; Nakata et al., 2010; Pau et al., 2013; Poikonen et al., 2018).

To conclude this discussion, we want to report some issues that can be seen as limitations of the present study. A first point concerns the sample size of our two groups ( 15 volunteers each). Although being in line with previous studies in literature, a larger number of participants would have increased the statistical power of the analysis, strengthening our findings. The great number of trials used to compute each of the ERP might nevertheless compensate for the relatively reduced sample size, even in a between-subject design. Another point lies in the fact that a visual control condition was not included in this investigation. After practicing with imagery training, our volunteers were instructed to observe and mentally imitate a series of movements. No behavioural response was required or measured; thus, we can't exclude a fluctuation in the attentional level of our participants during the experiment. Regardless, the number and order of stimuli in each sequence were counterbalanced between categories. So, an effect of general decreased attention would not likely account for the effort-related sensitivity of P300 and LP components found in this study.

\section{Conclusion}

The present EEG study investigated the time course and neural correlates of effort encoding in complex action representation by presenting videos of technical ballet steps to dancers and controls. The observation of action effort elicited a positive component over frontal sites, possibly associated with action encoding, coinciding with the maximum peak of displayed effort. Control participants who lack dance-specific motor knowledge likely experienced increased cognitive demands (larger occipital LP, rPFC engagement estimated by SWLORETA) as a result of the encoding of uncharacteristically large volumes of kinematic details needed to mentally reproduce the movement. At the same time, the dancers showed a refined ability (i.e., visuomotor processing) to encode effort information during action observation, as suggested by the effort-related modulation of both frontal P300 and parietal LP components, and the recruitment of frontoparietal regions (swLORETA). Consistent with the "neural efficiency" perspective, the neural representation of the observed action acquired through dance training possibly leads to enhanced visuomotor simulation processes that, in turn, require fewer cognitive resources for perceiving effort during action observation and encoding.

Overall, these pieces of evidence seem to suggest a role of frontoparietal regions in effort encoding during complex action observation, especially in dance experts. Our results are consistent with previous studies on simple actions and implicit motion perception that showed 
Table 2

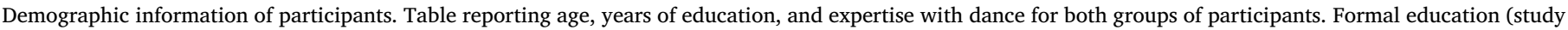
level), the age of acquisition, dance training, professional, and teaching activity are expressed in years.

\begin{tabular}{|c|c|c|c|c|c|c|c|c|}
\hline & \multicolumn{6}{|c|}{ DANCERS } & \multicolumn{2}{|c|}{ CONTROLS } \\
\hline & Age & $\begin{array}{c}\text { Formal } \\
\text { education }\end{array}$ & $\begin{array}{c}\text { Age of } \\
\text { Acquisition }\end{array}$ & $\begin{array}{l}\text { Dance } \\
\text { training }\end{array}$ & $\begin{array}{c}\text { Professional } \\
\text { activity } \\
\text { (dancer or } \\
\text { choreographer) }\end{array}$ & $\begin{array}{l}\text { Teaching } \\
\text { activity }\end{array}$ & Age & $\begin{array}{c}\text { Formal } \\
\text { education }\end{array}$ \\
\hline & 20 & 13 & 5 & 15 & 1 & 1 & 30 & 16 \\
\hline & 28 & 19 & 6 & 22 & 4 & 4 & 27 & 16 \\
\hline & 26 & 13 & 6 & 20 & 8 & 8 & 22 & 13 \\
\hline & 27 & 13 & 3 & 24 & 6 & 5 & 30 & 18 \\
\hline & 23 & 13 & 10 & 13 & 6 & 1 & 22 & 13 \\
\hline & 21 & 13 & 3 & 11 & 3 & 0 & 22 & 13 \\
\hline & 22 & 13 & 7 & 15 & 6 & 2 & 22 & 13 \\
\hline & 25 & 13 & 6 & 20 & 8 & 5 & 24 & 13 \\
\hline & 23 & 13 & 3 & 20 & 1 & 1.5 & 22 & 13 \\
\hline & 30 & 16 & 5 & 20 & 7 & 3 & 25 & 16 \\
\hline & 23 & 16 & 5 & 18 & 4 & 5 & 25 & 16 \\
\hline & 22 & 13 & 4 & 18 & 5 & 0 & 24 & 16 \\
\hline & 24 & 13 & 4 & 20 & 4 & 0 & 29 & 18 \\
\hline & 32 & 13 & 3 & 29 & 6 & 13 & 24 & 16 \\
\hline & 23 & 13 & 3 & 20 & 6 & 6 & 26 & 18 \\
\hline Mean & 24.6 & 13.8 & 4.9 & 19 & 5 & 4 & 24.9 & 17 \\
\hline SD & 3.4 & 1.8 & 2 & 4.4 & 4.1 & 3.6 & 2.9 & 2.6 \\
\hline
\end{tabular}

the engagement of motor and visuomotor areas in processing effort in formation, respectively. Despite the lack of engagement of brain regions associated with mentalizing ability reported here, a possible integrative role in action observation cannot be entirely excluded. Further studies will be required to disentangle the contribution of the AON and mentalizing system in action processing and representation.

\section{Materials and methods}

\subsection{Participants}

Thirty healthy female volunteers participated in this investigation. Fifteen were professional ballet dancers (mean age 24.6 years, $\mathrm{SD}=3.4)$ with 9 years of academic training (SD $=3$ ) on average. In general, they began studying dance (age of acquisition) at the age of 5 (mean age 4.5 years, SD $=2$ ), so that they had an overall dance experience of 19 years $(S D=4.4)$. The other fifteen were control university students (mean age 24.9 years, $S D=2.9$ ) without any motor or visual experience with dance, gymnastics, or martial arts (the demographic information of the participants is listed in Table 2). To avoid an unpredictable confound of the opposite- vs. own-sex effects (during body perception), participants were all females, all right-handed and heterosexual. It was decided to consider the highest (as possible) level of expertise as a requirement to be included in the professional dancer group, approaching the methodological standard used in different research frameworks (i.e., neuroscience of music). In the case of dance, the research tradition is more recent, and thus, the methodological guidelines regulating the inclusion/exclusion criteria for participants' selection are less consistent. It was also fundamental to consider two groups with extremely polarized (excellent vs. null) dance expertise to elicit, as hypothesized, different engagement of neural networks underlying action representation modulated by acquired expertise. In this regard, our group of dancers included only certified professional dancers coming from major national opera houses and academies. This decision led to reduced availability of participants in the time-window established for study planning and data recording. Finally, all volunteers had a normal or corrected-to-normal vision and reported no history of neurological illness or drug abuse. The Italian version of the Edinburgh Handedness Inventory was employed to assess right-handedness. The experiments were conducted with the understanding and the written consent of each volunteer, in addition to the approval of the ethical committee of the University of Milano-Bicocca.

\subsection{Stimuli preparation}

354 colour video clips that lasted $2 \mathrm{~s}$ were created for employment as stimulus material. In each video, a professional male ballet dancer (one of 6 dancers) performed a movement belonging to the ballet repertoire. In particular, $95 \%$ of the stimuli were standard steps belonging to technique common to both male and female dancers (5\% from male technique). Two categories of videos were created according to the effort required to perform the steps. 177 video clips represented effortful movements while 177 video clips represented effortless movements (the list of movements is reported in Table 3). Stimuli were created and synchronized so that after $1000 \mathrm{~ms}$, the peak of maximum effort occurred in both categories of movement (e.g., highest legs opening or limb extension during jumps, maximum muscular contraction during balances and pirouettes). An example of effortful and effortless stimuli is shown in Fig. 1 (see also Video 1 in the supplementary material). Since there is greater skeletal muscle mass reported in male than female individuals (Janssen et al., 2000), all actors were male dancers, thereby maximizing the effort information conveyed by muscle contraction and action kinematics (Alaerts et al., 2010b). The dancers were wearing similar adherent black clothes in order to show their musculature, and entire body was well visible. Recordings were made in an empty rehearsal room with a light grey background and floor in order to minimize environmental distractors. High definition videos were recorded with a frame rate of $25 \mathrm{fps}$ using a Nikon D7000 Reflex. The camera was fixed to a tripod at an equal distance for all dancers so that it could be moved on the horizontal plane to follow the moving dancer and to keep him at the center of the scene. Post-production video editing was realized using Adobe Premiere Pro CC 2015 (version 
Table 3

List of movements. The table illustrates the list of technical gestures recorded from 6 professional dancers on the basis of the muscular effort required by the performance. Effortful movements are reported in the left column; effortless movements are reported in the right column.

\begin{tabular}{|c|c|}
\hline Effortful & Effortless \\
\hline Pirouettes en dedans passé & Pirouette en dedans passé \\
\hline Pirouettes en dehors passé & Pirouette en dehors passé \\
\hline Pirouettes en dedans en attitude devant & $\begin{array}{l}\text { Pirouette en dedans en attitude } \\
\text { devant }\end{array}$ \\
\hline Pirouettes en dehors en attitude devant & $\begin{array}{l}\text { Pirouette en dehors en attitude } \\
\text { devant }\end{array}$ \\
\hline Pirouettes en dedans en attitude derrière & Pirouette en dedans sur le cou-de-pied \\
\hline Pirouettes en dehors en attitude derrière & $\begin{array}{l}\text { Pirouette en dehors en attitude } \\
\text { derrière }\end{array}$ \\
\hline Pirouettes à la seconde & Battement tendu à la seconde \\
\hline Fouetté & $\begin{array}{l}\text { Pirouette en dedans en attitude } \\
\text { derrière }\end{array}$ \\
\hline Développé $>90^{\circ}$ & Développé à la seconde à terre \\
\hline Grand battements en cloche & Battements tendu en cloche \\
\hline Tours chaînés déboulés vite & Tours chaînés déboulés lents \\
\hline Sissonne en avant & Pas en avant \\
\hline Sissonne de côté & Echappé \\
\hline Sissonne changé & Glissade en avant \\
\hline Brisé & Assemblé \\
\hline Brisé volé & Arabesque croisée \\
\hline Grand assemblé en tournant & Pas de bourrée \\
\hline Entrechat six & Changement de pieds \\
\hline Temps levé & Chassé \\
\hline Renversé sauté & Port de bras \\
\hline Rond sauté & Rond de jambe à terre en dehors \\
\hline Entrelacé & Développé arabesque \\
\hline Grand jetè à la seconde & Glissade derrière \\
\hline Grand jeté en tournant à l'arabesque & Soutenu en tournant \\
\hline Grand jeté en tournant à l'attitude & Renversé \\
\hline Cabriole battue derrière & Battement tendu an arrière \\
\hline Cabriole battue devant & Battement tendu en avant \\
\hline Saut de basque & Pirouette en dehors sur le cou-de-pied \\
\hline Rond de jambe en l'air & $\begin{array}{l}\text { Rond de jambe à terre en pliè en } \\
\text { dedans }\end{array}$ \\
\hline Rond en l'air sauté & Rond de jambe à terre en dedans \\
\hline Battement fondu relevé devant & Battement fondu développé devant \\
\hline Battement fondu relevé à la seconde & $\begin{array}{l}\text { Battement fondu développé à la } \\
\text { seconde }\end{array}$ \\
\hline Battement fondu relevé derrière & Battement fondu développé derrière \\
\hline Pirouette piqué en dehors & Chassé en tournant \\
\hline Pirouette en arabesque $45^{\circ}$ & Arabesque ouverte \\
\hline Saut de chat & Tombé - pas de bourrée \\
\hline Tour en l'air & Soubresaut \\
\hline Pas de ciseaux & Rond de jambe en pliè ne dehors \\
\hline Pas de basque & Soutenu \\
\hline Pas de chat & Pas de valse en tournant \\
\hline Penché & Piqué en attitude \\
\hline
\end{tabular}

9.0). The final size of the videos was $32 \times 23 \mathrm{~cm}$, subtending a visual angle of $15^{\circ} 18^{\prime} \times 11^{\circ} 15^{\prime}$. Both classes of videos were equiluminant. No difference in stimulus luminance as a function of stimulus type was shown by ANOVA (effortful $=1.76 \mathrm{fL}$, effortless $=1.73 \mathrm{fL}, p=0.69$ ).

\subsection{Stimuli validation}

To assess whether the stimuli were really perceived as effortful or relatively effortless by professional dancers, a validation procedure was carried out. A sample of twenty female judges were recruited, in particular, ten of them were professional dancers (mean age 38.9 years, $\mathrm{SD}=11.2)$ with a mean dance experience of 26 years (26.2 years, $\mathrm{SD}=8.7$ ) while the other ten were control volunteers without any physical or visual experience with dance (mean age 39.7 years, $\mathrm{SD}=15$ ). All 354 stimuli were displayed at the center of a screen in pseudo-randomized order through a PowerPoint presentation. Participants were instructed to rate each stimulus by verbally indicating the degree of muscular effort required to perform the movement (i.e., relatively little effort vs. considerable effort). The rating provided by the professional dancers were used for the video selection. Specifically, the videos for which the concordance between professionals was < $70 \%$ were discarded. According to the results of the validation process, 326 stimuli (163 effortful and 163 effortless, balanced for kinematic parameters and use of the space) were selected and used for the present study.

Furthermore, the ability of expert and non-expert judges to estimate the effective effort in each video was compared. The rating values of each judge were converted into a Boolean variable (relatively little effort $=0$ and considerable effort $=1$ ) and averaged within the two categories of movement (effortful vs. effortless). Thus, an ANOVA with one between-groups factor (group: dancers, controls) and one withingroups factor (effort: effortful, effortless) was performed on the individual ratings of perceived effort. A significant effect of effort factor was found $[\mathrm{F}(1,18)=1550.356, p<0.0001]$, showing a higher rate for effortful (0.87, $\mathrm{SE}=0.018)$ than effortless stimuli (0.11, $\mathrm{SE}=0.019$ ) regardless of judges' expertise level. A further effort X group interaction $[\mathrm{F}(1,18)=8.896, p<0.01]$ and the relevant Fisher's LSD posthoc test $(p<0.05)$ showed a significant difference on rating of effortful stimuli between dancers $(0.92, \mathrm{SE}=0.02$ ) and controls $(0.83, \mathrm{SE}=0.02)$. Contrarily, no difference between groups $(p=0.58)$ was found in response to effortless stimuli. Thus, this result might suggest that non-dancers underestimated the real effort required to perform several of the shown effortful movements (see Fig. 9).

\subsection{Task and procedure}

Before EEG-cap placement, the volunteers were presented with a motor imagery training to get them acquainted with the subsequent experimental task. Specifically, the experimenter reproduced in front of them a series of movements belonging to both daily-life (i.e., touch the floor, jump forward) and ballet (i.e., plié with feet in the first position, echapee) repertoire. For each movement, participants were instructed to perform twice the following tasks. First, observe the experimenter executing the step and reproduce it; second, observe the experimenter, reproduce the step and subsequently imagine doing the same without any real movement; third, observe the experimenter and imagine reproducing the step.

After EEG-cap placement, the participants were seated in an acoustically and electrically shielded cabin, facing a high-resolution VGA computer screen $114 \mathrm{~cm}$ away from their eyes. To minimize eye gazes, blinks, and body movements, they were instructed to look at a fixation cross at the center of the screen during EEG recording. Stimuli were presented using Eevoke v2.2 (ANT Neuro, Hengelo, The Netherlands). Each experimental trial started with the presentation of a video (2000 ms), followed by a red cross on an isoluminant light grey background that lasted $900 \mathrm{~ms} \pm 100 \mathrm{~ms}$ (interstimulus interval). After that, the cross changed in color, becoming blue and remaining visible for $3000 \mathrm{~ms}$ (an example of the experimental paradigm is provided in Fig. 2). The volunteers were instructed to observe each video and to imagine executing it as soon as the red fixation cross changed to blue (visual cue for imagery task). The motor imagery task was chosen because we were also interested in investigating the time courses and neural correlate of mental simulation as a function of effort and expertise. The results relevant to this second intention of study will be the focus of a different paper now under review (Orlandi et al., under review). Twelve different, randomly mixed, short experimental sequences of $2.88 \mathrm{~min}$ were created so that within each sequence, an equal number of effortful and effortless movements were shown. Kinematic parameters (e.g., body parts moving, limbs extension, use of the space) were kept as much as possible, similar between videos depicting a different degree of effort. The identity of the performing dancer changed every trial, and stimuli were counterbalanced for the displayed dancer. Two additional sequences of movements (different from those 
shown during EEG recording) were used in a training phase before EEG recording, to allow the participants to familiarize with the task and experimental setting and teach them how to reduce the eyes and body movements/tension (main causes of artifacts). All the participants were blinded to the aim of the study and stimuli properties.

\subsection{EEG recording and data analysis}

EEG was continuously recorded from 128 scalp sites located according to the 10-5 International System (Oostenveld and Praamstra, 2001) at a sampling rate of $512 \mathrm{~Hz}$. EEProbe v2.2 (ANT Neuro, Hengelo, The Netherlands) was used for both data recording and analysis. Horizontal and vertical eye movements were also recorded (electrooculogram, EOG) using 4 electrodes embedded in the EEG-cap. Eletrodes were palced on the outer canthus of both eyes, and above the eyebrows. Averaged mastoids (2 electrodes placed over the mastoid bones) served as the reference lead. The EEG and EOG were amplified and filtered with a half-amplitude band-pass of $0.16-70 \mathrm{~Hz}$ and a notch of $50 \mathrm{~Hz}$. Electrode impedance was kept below $5 \mathrm{k} \Omega$. Computerized artifact rejection was performed before averaging to discard epochs in which eye movements, blinks, excessive muscle potentials, or amplifier blocking occurred. The rejection criterion for this automatized procedure was based on peak-to-peak amplitudes exceeding $50 \mu \mathrm{V}$ and applied to the entire EEG recordings. EEGs were also manually inspected to avoid any undetected artifact. EEG epochs were synchronized with the onset of the video. ERPs were averaged off-line from $-100 \mathrm{~ms}$ before to $2000 \mathrm{~ms}$ after stimulus onset and filtered with a band-pass of 0.16-15 Hz. Overall, 74\% of recorded trials were used for ERP averaging (mean trials $=121$ ). Repeated-measure ANOVA performed on the percentage of valid trials (with effort as within-subject factor and group as between-subject factor) showed no significant effects (group: $p=0.16$; effort: $p=0.93$ : group*effort: $p=0.35$ ). ERP components were identified and measured with reference to the average baseline voltage calculated over the $100 \mathrm{~ms}$ before the stimulus onset at sites and latency when maximum amplitude was reached (Picton et al., 2000), and based on previous literature (P300-like: Dolcos and Cabeza, 2002; Mangels et al., 2001; Orlandi et al., under review; LP: Proverbio et al., 2009; Sitnikova et al., 2008). ERP averages were computed as a function of group and stimulus type. The mean area voltage of the frontal P300 component was measured at Fp1, Fp2, AFp3h, and AFp4h electrode sites during the 1050-1250 ms time-window. The visual inspection and measurement of the grand-average ERP waveforms showed the maximum positive peak at approximately $1140 \mathrm{~ms}$. The $200 \mathrm{~ms}$ time-window was arbitrarily chosen to incorporate these peaks in all participants, including equally the ascending and descending slopes of the P300. The mean area voltage of the parieto-occipital Late Positivity (LP) component was measured at P1, P2, POO3h, and POO4h electrode sites during the $1400-1600 \mathrm{~ms}$ time-window. The visual inspection and measurements of ERP waveforms, at both grand-average and single subject levels, allowed us to identify the moment of maximum difference between conditions (effortful vs. effortless) visible in all participants (i.e., arbitrary $200 \mathrm{~ms}$ time-window). The effect size for the statistically significant factors was estimated using partial eta squared $\left(\eta_{p}^{2}\right)$.

Overall, the ERP data were subjected to multifactorial repeatedmeasures ANOVA with one between-groups factor (group: dancers, controls) and three within-groups factors, including: effort (effortful, effortless), hemisphere (left, right), and electrode (Fp1-2 and AFp3h-4 h for the P300; P1-2 and POO3h-4 h for the LP) factors. Standardized and Weighted Low-Resolution Electromagnetic Tomography (swLORETA) was applied to the difference waves obtained by subtracting the ERPs for the effortless stimuli from those elicited by effortful stimuli between 1400 and $1600 \mathrm{~ms}$ in both groups of participants. The selection of the LP (1400-1600 ms) time-window was based on the significant effects shown by the ANOVA in both gorups of participants.
LORETA, which is a discrete linear solution to the inverse EEG problem, corresponds to the 3-D distribution of neuronal electric activity that yields maximum similarity (i.e., maximum synchronization), in terms of orientation and strength, between neighboring neuronal populations (represented by adjacent voxels). In this study, an improved version of the sLORETA (standardized low-resolution electromagnetic tomography) was used, which incorporates a singular value decomposition-based lead field weighting (swLORETA; Palmero-Soler et al., 2007). The following characteristics for source space were included: five points of grid spacing (the distance between two calculation points) and estimated SNR (Signal-to-Noise Ratio defines the regularization; a higher SNR value leads to less regularization and less blurred results) equal to three. LORETA was performed on group data to identify statistically significant electromagnetic dipoles $(p<0.05)$, in which as the magnitude increases, the significance of the group differences increases.

\section{CRediT authorship contribution statement}

Andrea Orlandi: Conceptualization, Methodology, Formal analysis, Investigation, Writing - original draft. Silvia D'Incà: Investigation, Validation. Alice Mado Proverbio: Conceptualization, Methodology, Supervision, Writing - review \& editing.

\section{Declaration of Competing Interest}

The authors declare that they have no known competing financial interests or personal relationships that could have appeared to influence the work reported in this paper.

\section{Acknowledgments}

We are very grateful to Tatiana Baroni for her technical support and to Elisa Arno for her very precious help. Special thanks go to six dancers who performed the dance steps to be used as stimuli for the study, and to all the professional dancers and controls who took part in the EEG study.

\section{Appendix A. Supplementary data}

Supplementary data to this article can be found online at https:// doi.org/10.1016/j.brainres.2020.146712.

\section{References}

Abreu, A.M., Macaluso, E., Azevedo, R.T., Cesari, P., Urgesi, C., Aglioti, S.M., 2012. Action anticipation beyond the action observation network: a functional magnetic resonance imaging study in expert basketball players. Eur. J. Neurosci. 35 (10), 1646-1654. https://doi.org/10.1111/j.1460-9568.2012.08104.x.

Aglioti, S.M., Cesari, P., Romani, M., Urgesi, C., 2008. Action anticipation and motor resonance in elite basketball players. Nat. Neurosci. 11 (9), 1109-1116. https://doi. org/10.1038/nn.2182.

Alaerts, K., Swinnen, S.P., Wenderoth, N., 2009. Is the human primary motor cortex activated by muscular or direction-dependent features of observed movements? Cortex 45 (10), 1148-1155. https://doi.org/10.1016/j.cortex.2008.10.005.

Alaerts, K., Senot, P., Swinnen, S.P., Craighero, L., Wenderoth, N., Fadiga, L., 2010a. Force requirements of observed object lifting are encoded by the observer's motor system: a TMS study. Eur. J. Neurosci. 31 (6), 1144-1153. https://doi.org/10.1111/j. 1460-9568.2010.07124.x.

Alaerts, K., Swinnen, S.P., Wenderoth, N., 2010b. Observing how others lift light or heavy objects: which visual cues mediate the encoding of muscular force in the primary motor cortex? Neuropsychologia 48 (7), 2082-2090. https://doi.org/10.1016/j. neuropsychologia.2010.03.029.

Alaerts, K., de Beukelaar, T.T., Swinnen, S.P., Wenderoth, N., 2012. Observing how others lift light or heavy objects: time-dependent encoding of grip force in the primary motor cortex. Psychol. Res. 76 (4), 503-513. https://doi.org/10.1007/s00426-0110380-1.

Amoruso, L., Couto, J.B., Ibanez, A., 2011. Beyond Extrastriate Body Area (EBA) and Fusiform Body Area (FBA): context integration in the meaning of actions. Front. Hum. Neurosci. 5, 124. https://doi.org/10.3389/fnhum.2011.00124.

Amoruso, L., Sedeño, L., Huepe, D., Tomio, A., Kamienkowski, J., Hurtado, E., Cardona, J.F., Álvarez González, M.Á., Rieznik, A., Sigman, M., Manes, F., Ibáñez, A., 2014. 
Time to tango: expertise and contextual anticipation during action observation. Neuroimage 98, 366-385. https://doi.org/10.1016/j.neuroimage 2014.05.005.

Arnstein, D., Cui, F., Keysers, C., Maurits, N.M., Gazzola, V., 2011. $\mu$-suppression during action observation and execution correlates with BOLD in dorsal premotor, inferior parietal, and SI cortices. J. Neurosci. 31 (40), 14243-14249. https://doi.org/10. 1523/JNEUROSCI.0963-11.2011.

Avenanti, A., Bolognini, N., Maravita, A., Aglioti, S.M., 2007. Somatic and motor components of action simulation. Curr. Biol. 17 (24), 2129-2135. https://doi.org/10. 1016/j.cub.2007.11.045.

Azizian, A., Freitas, A.L., Watson, T.D., Squires, N.K., 2006. Electrophysiological correlates of categorization: P300 amplitude as index of target similarity. Biol. Psychol. 71 (3), 278-288. https://doi.org/10.1016/j.biopsycho.2005.05.002.

Babiloni, C., Marzano, N., Infarinato, F., Iacoboni, M., Rizza, G., Aschieri, P., Cibelli, G., Soricelli, A., Eusebi, F., Del Percio, C., 2010. "Neural efficiency" of experts' brain during judgment of actions: a high-resolution EEG study in elite and amateur karate athletes. Behav. Brain Res. 207 (2), 466-475. https://doi.org/10.1016/j.bbr.2009. 10.034.

Bayer, M., Schacht, A., 2014. Event-related brain responses to emotional words, pictures, and faces - across-domain comparison. Front. Psychol. 5. https://doi.org/10.3389/ fpsyg.2014.01106.

Benoit, R.G., Gilbert, S.J., Frith, C.D., Burgess, P.W., 2011. Rostral prefrontal cortex and the focus of attention in prospective memory. Cereb. Cortex 22 (8), 1876-1886. https://doi.org/10.1093/cercor/bhr264.

Binder, E., Dovern, A., Hesse, M.D., Ebke, M., Karbe, H., Saliger, J., Fink, G.R., Weiss, P.H., 2017. Lesion evidence for a human mirror neuron system. Cortex 90, 125-137. https://doi.org/10.1016/j.cortex.2017.02.008.

Bonini, L., 2016. The extended mirror neuron network anatomy, origin, and functions. Neuroscientist 1-12. https://doi.org/10.1177/1073858415626400.

Bradley, M.M., Hamby, S., Löw, A., Lang, P.J., 2007. Brain potentials in perception: picture complexity and emotional arousal. Psychophysiology 44 (3), 364-373. https://doi.org/10.1111/j.1469-8986.2007.00520.x.

Buccino, G., Binkofski, F., Fink, G.R., Fadiga, L., Fogassi, L., Gallese, V., Seitz, R.J., Zilles, K., Rizzolatti, G., Freund, H.-J., 2001. Action observation activates premotor and parietal areas in a somatotopic manner: an fMRI study. Eur. J. Neurosci. 13, 400-404. https://doi.org/10.1111/j.1460-9568.2001.01385.x.

G. Buccino F. Lui N. Canessa I. Patteri G. Lagravinese F. Benuzzi C.A. Porro G. Rizzolatti Neural circuits involved in the recognition of actions performed by nonconspecifics: an fMRI study. J. Cognit. Neurosci. 16 (1), 2004 114-126. doi: 10.1162/ 089892904322755601.

Calvo-Merino, B., Glaser, D.E., Grèzes, J., Passingham, R.E., Haggard, P., 2005. Action observation and acquired motor skills: an fMRI study with expert dancers. Cereb. Cortex 15, 1243-1249. https://doi.org/10.1093/cercor/bhi007.

Calvo-Merino, B., Grezes, J., Glaser, D.E., Passingham, R.E., Haggard, P., 2006. Seeing or doing influence of visual and motor familiarity in action observation. Curr. Biol. 16, 1905-1910. https://doi.org/10.1016/j.cub.2006.07.065.

Calvo-Merino, B., Ehrenberg, S., Leung, D., Haggard, P., 2010. Experts see it all: configural effects in action observation. Psychol. Res. PRPF 74 (4), 400-406. https://doi. org/10.1007/s00426-009-0262-y.

Catmur, C., 2015. Understanding intentions from actions: direct perception, inference, and the roles of mirror and mentalizing systems. Conscious. Cogn. 36, 426-433. https://doi.org/10.1016/j.concog.2015.03.012.

Cattaneo, L., Rizzolatti, G., 2009. The mirror neuron system. Arch. Neurol. 66 (5), 557-560. https://doi.org/10.1001/archneurol.2009.41.

Cattaneo, L., Sandrini, M., Schwarzbach, J., 2010. State-dependent TMS reveals a hierarchical representation of observed acts in the temporal, parietal, and premotor cortices. Cereb. Cortex 20 (9), 2252-2258. https://doi.org/10.1093/cercor/bhp291.

Caspers, S., Zilles, K., Laird, A.R., Eickhoff, S.B., 2010. ALE meta-analysis of action observation and imitation in the human brain. Neuroimage 50 (3), 1148-1167. https:// doi.org/10.1016/j.neuroimage.2009.12.112.

Chiu, L.Z., 2018. Biomechanical methods to quantify muscle effort during resistance exercise. J. Streng. Condition. Res. 32 (2), 502-513. https://doi.org/10.1519/JSC. 0000000000002330.

Chong, T.T.J., Cunnington, R., Williams, M.A., Kanwisher, N., Mattingley, J.B., 2008 fMRI adaptation reveals mirror neurons in human inferior parietal cortex. Curr. Biol. 18 (20), 1576-1580. https://doi.org/10.1016/j.cub.2008.08.068.

Codispoti, M., Ferrari, V., Bradley, M.M., 2007. Repetition and event-related potentials: distinguishing early and late processes in affective picture perception. J. Cognit. Neurosci. 19 (4), 577-586. https://doi.org/10.1162/jocn.2007.19.4.577.

Coll, M.P., Press, C., Hobson, H., Catmur, C., Bird, G., 2017. Crossmodal classification of Mu Rhythm activity during action observation and execution suggests specificity to somatosensory features of actions. J. Neurosci. 37 (24), 5936-5947. https://doi.org/ 10.1523/JNEUROSCI.3393-16.2017.

Cross, E.S., Hamilton, A.F., de, C, Grafton, S.T., 2006. Building a motor simulation de novo: observation of dance by dancers. NeuroImage 31 (3), 1257-1267. https://doi. org/10.1016/j.neuroimage.2006.01.033.

Cross, E.S., Kraemer, D.J.M., de C, A.F., Kelley, W.M., Grafton, S.T., 2009. Sensitivity of the action observation network to physical and observational learning. Cereb. Cortex 19, 315-326. https://doi.org/10.1093/cercor/bhn083.

De Gelder, B., de Borst, A.W., Watson, R., 2015. The perception of emotion in body expressions. Wiley Interdiscip. Rev. Cognit. Sci. 6 (2), 149-158. https://doi.org/10. 1002/wcs.1335.

Decety, J., Jeannerod, M., Germain, M., Pastene, J., 1991. Vegetative response during imagined movement is proportional to mental effort. Behav. Brain Res. 42 (1), 1-5. https://doi.org/10.1016/S0166-4328(05)80033-6.

Denis, D., Rowe, R., Williams, A.M., Milne, E., 2017. The role of cortical sensorimotor oscillations in action anticipation. NeuroImage 146, 1102-1114. https://doi.org/10. 1016/j.neuroimage.2016.10.022.

Di Pellegrino, G., Fadiga, L., Fogassi, L., Gallese, V., Rizzolatti, G., 1992. Understanding motor events: a neurophysiological study. Exp. Brain Res. 91 (1), 176-180. https:// doi.org/10.1007/BF00230027.

Dolcos, F., Cabeza, R., 2002. Event-related potentials of emotional memory: encoding pleasant, unpleasant, and neutral pictures. Cognit. Affect. Behav. Neurosci. 2 (3), 252-263. https://doi.org/10.3758/CABN.2.3.252.

Erickson, L.C., Rauschecker, J.P., Turkeltaub, P.E., 2017. Meta-analytic connectivity modeling of the human superior temporal sulcus. Brain Struct. Funct. 222 (1), 267-285. https://doi.org/10.1007/s00429-016-1215-z.

Fox, N.A., Bakermans-Kranenburg, M.J., Yoo, K.H., Bowman, L.C., Cannon, E.N., Vanderwert, R.E., Ferrari, P.F., van IJzendoorn, M.H., 2016. Assessing human mirror activity with EEG mu rhythm: a meta-analysis. Psychol. Bull. 142 (3), 291-313. https://doi.org/10.1037/bul0000031.

Frith, C.D., Frith, U., 2006. The neural basis of mentalizing. Neuron 50 (4), 531-534. https://doi.org/10.1016/j.neuron.2006.05.001.

Gallese, V., Fadiga, L., Fogassi, L., Rizzolatti, G., 1996. Action recognition in the premotor cortex. Brain 119 (2), 593-609. https://doi.org/10.1093/brain/119.2.593.

Gardner, T., Goulden, N., Cross, E.S. (2015). Dynamic modulation of the action observation network by movement familiarity. J. Neurosci. 35 (4), 1561-1572. doi: 10. 1523/JNEUROSCI.2942-14.2015.

Gazzola, V., Keysers, C., 2008. The observation and execution of actions share motor and somatosensory voxels in all tested subjects: single-subject analyses of unsmoothed fMRI data. Cereb. Cortex 19 (6), 1239-1255. https://doi.org/10.1093/cercor/ bhn181.

Giacosa, C., Karpati, F.J., Foster, N.E., Penhune, V.B., Hyde, K.L., 2016. Dance and music training have different effects on white matter diffusivity in sensorimotor pathways. NeuroImage 135, 273-286. https://doi.org/10.1016/j.neuroimage.2016.04.048.

Giglio, A.C., Minati, L., Boggio, P.S., 2013. Throwing the banana away and keeping the peel: neuroelectric responses to unexpected but physically feasible action endings. Brain Res. 1532, 56-62. https://doi.org/10.1016/j.brainres.2013.08.017.

Gilbert, S.J., Spengler, S., Simons, J.S., Steele, J.D., Lawrie, S.M., Frith, C.D., Burgess, P.W., 2006. Functional specialization within rostral prefrontal cortex (area 10): a meta-analysis. J. Cognit. Neurosci. 18 (6), 932-948. https://doi.org/10.1162/jocn. 2006.18.6.932.

Grafton, S.T., 2009. Embodied cognition and the simulation of action to understand others. Ann. N. Y. Acad. Sci. 1156 (1), 97-117. https://doi.org/10.1111/j.17496632.2009.04425.x.

Grafton, S.T., de Hamilton, A.F., 2007. Evidence for a distributed hierarchy of action representation in the brain. Hum. Mov. Sci. 26 (4), 590-616. https://doi.org/10. 1016/j.humov.2007.05.009.

Grossman, E., Donnelly, M., Price, R., Pickens, D., Morgan, V., Neighbor, G., Blake, R., 2006. Brain areas involved in perception of biological motion. Brain 12 (5). https:// doi.org/10.1162/089892900562417.

Habib, R., Nyberg, L., Tulving, E., 2003. Hemispheric asymmetries of memory: the HERA model revisited. Trend. Cognit. Sci. 7 (6), 241-245. https://doi.org/10.1016/S13646613(03)00110-4.

Hajcak, G., Dunning, J.P., Foti, D., 2009. Motivated and controlled attention to emotion: time-course of the late positive potential. Clin. Neurophysiol. 120 (3), 505-510. https://doi.org/10.1016/j.clinph.2008.11.028.

Hajcak, G., MacNamara, A., Foti, D., Ferri, J., Keil, A., 2013. The dynamic allocation of attention to emotion: simultaneous and independent evidence from the late positive potential and steady state visual evoked potentials. Biol. Psychol. 92 (3), 447-455. https://doi.org/10.1016/j.biopsycho.2011.11.012.

Halahalli, H.N., John, J.P., Lukose, A., Jain, S., Kutty, B.M., 2015. Endogenous-cue prospective memory involving incremental updating of working memory: an fMRI study. Brain Struct. Funct. 220 (6), 3611-3626. https://doi.org/10.1007/s00429-0140877-7.

Hamilton, A.F., de, C., Grafton, S.T., 2006. Goal representation in human anterior intraparietal sulcus. J. Neurosci. 26 (4), 1133-1137. https://doi.org/10.1523/ JNEUROSCI.4551-05.2006.

Hamilton, A.F., de, C., Grafton, S.T., 2007. Action outcomes are represented in human inferior frontoparietal cortex. Cereb. Cortex 18 (5), 1160-1168. https://doi.org/10. 1093/cercor/bhm150.

Hänggi, U., Koeneke, S., Bezzola, L., Jäncke, L., 2010. Structural neuroplasticity in the sensorimotor network of professional female ballet dancers. Hum. Brain Mapp. 31, 1196-1206. https://doi.org/10.1002/hbm.20928.

Handjaras, G., Bernardi, G., Benuzzi, F., Nichelli, P.F., Pietrini, P., Ricciardi, E., 2015. A topographical organization for action representation in the human brain. Hum. Brain Mapp. 36 (10), 3832-3844. https://doi.org/10.1002/hbm.22881.

Hardwick, R.M., Caspers, S., Eickhoff, S.B., Swinnen, S.P., 2018. Neural correlates of action: comparing meta-analyses of imagery, observation, and execution. Neurosci. Biobehav. Rev. 94, 31-44. https://doi.org/10.1016/j.neubiorev.2018.08.003.

Haxby, J.V., Hoffman, E.A., Gobbini, M.I., 2000. The distributed human neural system for face perception. Trend. Cognit. Sci. 4 (6), 223-233. https://doi.org/10.1016/S13646613(00)01482-0.

Herrington, J.D., Nymberg, C., Schultz, R.T., 2011. Biological motion task performance predicts superior temporal sulcus activity. Brain Cogn. 77 (3), 372-381. https://doi. org $/ 10.1016 / j$.bandc.2011.09.001.

Hobson, H.M., Bishop, D.V., 2017. The interpretation of mu suppression as an index of mirror neuron activity: past, present and future. 160662. R. Soc. Open Sci. 4 (3). https://doi.org/10.1098/rsos.160662.

Hüfner, K., Binetti, C., Hamilton, D.A., Stephan, T., Flanagin, V.L., Linn, J., Labudda, K., Markowitsch, H., Glasauer, S., Jahn, K., Strupp, M., Brandt, T., 2011. Structural and functional plasticity of the hippocampal formation in professional dancers and slackliners. Hippocampus 21, 855-865. https://doi.org/10.1002/hipo.20801. 
Iacoboni, M., Molnar-Szakacs, I., Gallese, V., Buccino, G., Mazziotta, J.C., Rizzolatti, G. (2005). Grasping the intentions of others with one's own mirror neuron system. PLoS Biol. 3 (3). http://dx.doi:10.1371/journal.pbio.0030079.

Janssen, I., Heymsfield, S.B., Wang, Z., Ross, R., 2000. Skeletal muscle mass and distribution in 468 men and women aged 18-88 yr. J. Appl. Physiol. 89 (1), 81-88. https://doi.org/10.1152/jappl.2000.89.1.81.

Karpati, F.J., Giacosa, C., Foster, N.E., Penhune, V.B., Hyde, K.L. (2017). Dance and music share grey matter structural correlates. Brain Res., 1657, 62-73. doi: 10. 1016/j. brainres.2016.11.029.

Kilner, J.M., 2011. More than one pathway to action understanding. Trend. Cognit. Sci. 15 (8), 352-357. https://doi.org/10.1016/j.tics.2011.06.005.

Kilner, J.M., Friston, K.J., Frith, C.D., 2007. Predictive coding: an account of the mirror neuron system. Cognit. Process. 8 (3), 159-166. https://doi.org/10.1007/s10339007-0170-2.

Kirsch, L.P., Cross, E.S., 2015. Additive routes to action learning: layering experience shapes engagement of the action observation network. Cereb. Cortex 25 (12), 4799-4811. https://doi.org/10.1093/cercor/bhv167.

Koenig, S., Mecklinger, A., 2008. Electrophysiological correlates of encoding and retrieving emotional events. Emotion 8 (2), 162. https://doi.org/10.1037/1528-3542. 8.2.162.

Lingnau, A., Petris, S., 2012. Action understanding within and outside the motor system: the role of task difficulty. Cereb. Cortex 23 (6), 1342-1350. https://doi.org/10.1093/ cercor/bhs112.

Ma, F., Xu, J., Li, X., Wang, P., Wang, B., Liu, B., 2018. Investigating the neural basis of basic human movement perception using multi-voxel pattern analysis. Exp. Brain Res. 236 (3), 907-918. https://doi.org/10.1007/s00221-018-5175-9.

Makris, S., Urgesi, C., 2014. Neural underpinnings of superior action prediction abilities in soccer players. Soc. Cognit. Affect. Neurosci. 10 (3), 342-351. https://doi.org/10. 1093/scan/nsu052.

Mangels, J.A., Picton, T.W., Craik, F.I., 2001. Attention and successful episodic encoding: an event-related potential study. Cognit. Brain Res. 11 (1), 77-95. https://doi.org/ 10.1016/S0926-6410(00)00066-5.

Mier, D., Haddad, L., Diers, K., Dressing, H., Meyer-Lindenberg, A., Kirsch, P., 2014. Reduced embodied simulation in psychopathy. World J. Biol. Psychiatry 15 (6), 479-487. https://doi.org/10.3109/15622975.2014.902541.

Minamoto, T., Yaoi, K., Osaka, M., Osaka, N., 2015. The rostral prefrontal cortex underlies individual differences in working memory capacity: An approach from the hierarchical model of the cognitive control. Cortex 71, 277-290. https://doi.org/10. 1016/j.cortex.2015.07.025.

Mizuguchi, N., Nakata, H., Kanosue, K., 2016. The right temporoparietal junction encodes efforts of others during action observation. Sci. Rep. 6 (30274), 1-8. https://doi.org/ 10.1038/srep30274 1.

Molenberghs, P., Brander, C., Mattingley, J.B., Cunnington, R., 2010. The role of the superior temporal sulcus and the mirror neuron system in imitation. Hum. Brain Mapp. 31 (9), 1316-1326. https://doi.org/10.1002/hbm.20938.

Momennejad, I., Haynes, J.D., 2013. Encoding of prospective tasks in the human prefrontal cortex under varying task loads. J. Neurosci. 33 (44), 17342-17349. https:/ doi.org/10.1523/JNEUROSCI.0492-13.2013.

Moore, E., Schaefer, R.S., Bastin, M.E., Roberts, N., Overy, K., 2014. Can musical training influence brain connectivity? Evidence from diffusion tensor MRI. Brain Sci. 4 (2), 405-427. https://doi.org/10.3390/brainsci4020405.

Oostenveld, R., Praamstra, P. 2001. The five percent electrode system for high-resolution EEG and ERP measurements. Clin. Neurophysiol. 112(4):713-719. http://dx.doi. org/ 10.1016/S1388-2457(00)00527-7.

Orgs, G., Dombrowski, J.-H., Heil, M., Jansen-Osmann, P., 2008. Expertise in dance modulates alpha/beta event-related desynchronization during action observation. Eur. J. Neurosci. 27, 3380-3384. https://doi.org/10.1111/j.1460-9568.2008. 06271.x.

Orlandi, A., Arno, E., Proverbio, A. M. (under review). The effect of expertise on kinesthetic motor imagery of complex actions. Brain Topography.

Orlandi, A., Proverbio, A.M., 2019a. Bilateral engagement of the occipito-temporal cortex in response to dance kinematics in experts. Sci. Rep. 9 (1), 1000. https://doi.org/10. 1038/s41598-018-37876-x.

Orlandi, A., Proverbio, A.M., 2019b. Left-Hemispheric Asymmetry for Object-Based Attention: an ERP Study. Brain Sci. 9 (11), 315. https://doi.org/10.3390/ brainsci9110315.

Orlandi, A., Zani, A., Proverbio, A.M., 2017. Dance expertise modulates visual sensitivity to complex biological movements. Neuropsychologia 104, 168-181. https://doi.org/ 10.1016/j.neuropsychologia.2017.08.019.

Paccalin, C., Jeannerod, M., 2000. Changes in breathing during observation of effortful actions. Brain Res. 862 (1), 194-200. https://doi.org/10.1016/S0006-8993(00) 02145-4.

Palmero-Soler, E., Dolan, K., Hadamschek, V., Tass, P.A., 2007. swLORETA: a novel approach to robust source localization and synchronization tomography. Phys. Med. Biol. 52 (7), 1783-1800. https://doi.org/10.1088/0031-9155/52/7/002.

Panasiti, M.S., Pavone, E.F., Aglioti, S.M., 2016. Electrocortical signatures of detecting errors in the actions of others: an EEG study in pianists, musicians and musically naïve people. Neuroscience 318, 104-113. https://doi.org/10.1016/j. neuroscience. 2016.01.023.

Pau, S., Jahn, G., Sakreida, K., Domin, M., Lotze, M., 2013. Encoding and recall of finger sequences in experienced pianists compared with musically naive controls: a combined behavioral and functional imaging study. Neuroimage 64, 379-387. https:// doi.org/10.1016/j.neuroimage.2012.09.012.

Picton, T.W., 1992. The P300 wave of the human event-related potential. J. Clin. Neurophysiol. 9 (4), 456-479. https://doi.org/10.1097/00004691-199210000-
00002.

Picton, T.W., Bentin, S., Berg, P., Donchin, E., Hillyard, S.A., Johnson, R., Miller, G.A., Ritter, W., Ruchkin, D.S., Rugg, M.D., Taylor, M.J., 2000. Guidelines for using human event-related potentials to study cognition: recording standards and publication criteria. Psychophysiology 37 (02), 127-152. https://doi.org/10.1111/1469-8986. 3720127.

Peelen, M.V., Downing, P.E., 2007. The neural basis of visual body perception. Nat. Rev. Neurosci. 8 (8), 636-648. https://doi.org/10.1038/nrn2195.

Pobric, G., Hamilton, A.F.D.C., 2006. Action understanding requires the left inferior frontal cortex. Curr. Biol. 16 (5), 524-529. https://doi.org/10.1016/j.cub.2006.01. 033

Poikonen, H., Toiviainen, P., Tervaniemi, M., 2018. Dance on cortex: enhanced theta synchrony in experts when watching a dance piece. Eur. J. Neurosci. 47 (5), 433-445. https://doi.org/10.1111/ejn.13838.

Polich, J., 2007. Updating P300: an integrative theory of P3a and P3b. Clin. Neurophysiol. 118 (10), 2128-2148. https://doi.org/10.1016/j.clinph.2007.04.019.

Proverbio, A.M., Gabaro, V., Orlandi, A., Zani, A., 2015. Semantic brain areas are involved in gesture comprehension: an electrical neuroimaging study. Brain Lang. 147, 30-40. https://doi.org/10.1016/j.bandl.2015.05.002.

Proverbio, A.M., Riva, F., Zani, A. (2009). Observation of static pictures of dynamic actions enhances the activity of movement-related brain areas. PLoS ONE, 4, Issue 5, e5389:1-8. doi: 10.1371/journal.pone.0005389.

Quandt, L.C., Marshall, P.J., 2014. The effect of action experience on sensorimotor EEG rhythms during action observation. Neuropsychologia 56, 401-408. https://doi.org/ 10.1016/j.neuropsychologia.2014.02.015.

Ricciardi, E., Handjaras, G., Bonino, D., Vecchi, T., Fadiga, L., Pietrini, P., 2013. Beyond motor scheme: a supramodal distributed representation in the action-observation network. e58632. PLoS ONE 8 (3). https://doi.org/10.1371/journal.pone.0058632.

Rizzolatti, G., Craighero, L., 2004. The mirror-neuron system. Annu. Rev. Neurosci. 27, 169-192. https://doi.org/10.1146/annurev.neuro.27.070203.144230.

Rizzolatti, G., Sinigaglia, C., 2010. The functional role of the parieto-frontal mirror circuit: interpretations and misinterpretations. Neuroscience 11, 264-274. https://doi. org $/ 10.1038 / \mathrm{nrn} 2805$.

Rizzolatti, G., Sinigaglia, C., 2016. The mirror mechanism: a basic principle of brain function. Nat. Rev. Neurosci. 17 (12), 757-765. https://doi.org/10.1038/nrn.2016. 135

Rossion, B., 2014. Understanding face perception by means of human electrophysiology. Trend. Cognit. Sci. 18 (6), 310-318. https://doi.org/10.1016/j.tics.2014.02.013.

Rüber, T., Lindenberg, R., Schlaug, G., 2013. Differential adaptation of descending motor tracts in musicians. Cereb. Cortex 25 (6), 1490-1498. https://doi.org/10.1093/ cercor/bht331.

Schupp, H.T., Cuthbert, B.N., Bradley, M.M., Cacioppo, J.T., Ito, T., Lang, P.J., 2000. Affective picture processing: the late positive potential is modulated by motivational relevance. Psychophysiology 37 (2), 257-261. https://doi.org/10.1111/1469- 8986. 3720257.

Sitnikova, T., Kuperberg, G., Holcomb, P.J., 2003. Semantic integration in videos of real-world events: an electrophysiological investigation. Psychophysiology 40 (1) 160-164. https://doi.org/10.1111/1469-8986.00016.

Sitnikova, T., Holcomb, P.J., Kiyonaga, K.A., Kuperberg, G.R., 2008. Two neurocognitive mechanisms of semantic integration during the comprehension of visual real-world events. J. Cognit. Neurosci. 20 (11), 2037-2057. https://doi.org/10.1162/jocn. 2008.20143.

Smith, D.M., 2016. Neurophysiology of action anticipation in athletes: a systematic review. Neurosci. Biobehav. Rev. 60, 115-120. https://doi.org/10.1016/j.neubiorev. 2015.11.007.

Sokolov, A.A., Erb, M., Gharabaghi, A., Grodd, W., Tatagiba, M.S., Pavlova, M.A., 2012. Biological motion processing: the left cerebellum communicates with the right superior temporal sulcus. Neuroimage 59 (3), 2824-2830. https://doi.org/10.1016/j. neuroimage.2011.08.039.

Steele, C.J., Bailey, J.A., Zatorre, R.J., Penhune, V.B., 2013. Early musical training and white-matter plasticity in the corpus callosum: evidence for a sensitive period. J. Neurosci. 33 (3), 1282-1290. https://doi.org/10.1523/JNEUROSCI.3578-12.2013.

Thompson, J.C., Clarke, M., Stewart, T., Puce, A., 2005. Configural processing of biological motion in human superior temporal sulcus. J. Neurosci. 25 (39), 9059-9066. https://doi.org/10.1523/JNEUROSCI.2129-05.2005.

Tucciarelli, R., Turella, L., Oosterhof, N.N., Weisz, N., Lingnau, A., 2015. MEG multivariate analysis reveals early abstract action representations in the lateral occipitotemporal cortex. J. Neurosci. 35 (49), 16034-16045. https://doi.org/10.1523/ JNEUROSCI.1422-15.2015.

Valchev, N., Zijdewind, I., Keysers, C., Gazzola, V., Avenanti, A., Maurits, N.M., 2015 Weight dependent modulation of motor resonance induced by weight estimation during observation of partially occluded lifting actions. Neuropsychologia 66, 237-245. https://doi.org/10.1016/j.neuropsychologia.2014.11.030.

Vaquero, L., Hartmann, K., Ripollés, P., Rojo, N., Sierpowska, J., François, C., Càmara, E., Vugt, F.T., Mohammadi, B., Samii, A., Münte, T.F., Rodríguez-Fornells, A., Altenmüller, E., 2016. Structural neuroplasticity in expert pianists depends on the age of musical training onset. Neuroimage 126, 106-119. https://doi.org/10.1016/. neuroimage.2015.11.008.

Yin, S., Liu, Y., Ding, M., 2016. Amplitude of sensorimotor Mu rhythm is correlated with BOLD from multiple brain regions: a simultaneous EEG-fMRI study. Front. Hum. Neurosci. 10. https://doi.org/10.3389/fnhum.2016.00364.

Zénon, A., Sidibé, M., Olivier, E., 2015. Disrupting the supplementary motor area makes physical effort appear less effortful. J. Neurosci. 35 (23), 8737-8744. https://doi.org/ 10.1523/JNEUROSCI.3789-14.2015. 